\title{
Dielectric relaxation in a cadmium chloride-doped polymeric blend
}

\author{
BASAVARAJESHWARI M BARAKER and BLAISE LOBO* $\mathbb{C}$ \\ Department of Physics, Karnatak University's Karnatak Science College, Dharwad 580001, Karnataka, India \\ *Author for correspondence (blaise.lobo@gmail.com)
}

MS received 12 September 2017; accepted 12 April 2018; published online 18 January 2019

\begin{abstract}
The temperature- and frequency-dependent relaxation processes in films of a polymeric blend comprising a polyvinyl alcohol (PVA)/polyvinyl acetate (PVAc) co-polymer blended with polyvinyl pyrrolidone (PVP) in equal proportion by weight, and doped with an inorganic metallic salt, cadmium chloride $\left(\mathrm{CdCl}_{2}\right)$, at $0.0 \mathrm{wt} \%$ and $10.2 \mathrm{wt} \%$ doping levels (DLs), have been studied using dielectric relaxation spectroscopy (DRS). The frequency response of dielectric parameters for these samples has been studied with variation in temperature, from 303 up to $373 \mathrm{~K}$, at different fixed frequencies (from $12 \mathrm{~Hz}$ up to $200 \mathrm{kHz}$ ). Study of Cole-Cole plots reveals a decrease in bulk resistivity of the samples with increase in temperature, which is attributed to thermally induced increase in the mobility of polymer chains. A 10 -fold increase in bulk conductivity is observed for doped films with a DL of $10.2 \mathrm{wt} \%$, when compared with the bulk conductivity of the un-doped ( $0.0 \mathrm{wt} \% \mathrm{DL})$ sample. The temperature dependence of dielectric parameters at different frequencies has been studied and the activation energy has been calculated. The relaxation time is found to be of the order of a few milliseconds, which implies that electrical conduction in $\mathrm{CdCl}_{2}$-doped PVA/PVAc-PVP blend films is predominantly due to the migration of ions. The variation of AC conductivity with frequency is in agreement with Jonscher's universal power law. AC conductivity of the sample is found to increase significantly with an increase in temperature of the sample. Frequency-dependent dielectric properties of $\mathrm{CdCl}_{2}$-doped PVA/PVAc-PVP blend films, for various DLs, are also studied at room temperature.
\end{abstract}

Keywords. Cole-Cole plot; $\mathrm{CdCl}_{2}$-doped PVA/PVAc-PVP; dielectric loss; dielectric relaxation spectroscopy; electric modulus.

\section{Introduction}

Polyvinyl alcohol (PVA)-polyvinyl acetate (PVAc) copolymers and polyvinyl pyrrolidone (PVP) are polymeric materials which are easily soluble in water, easily processable and have good film forming ability. The dielectric properties of PVA/PVAc-PVP blend films are attributed to the orientation of $\mathrm{N}-\mathrm{O}$ and $\mathrm{C}=\mathrm{O}$ groups. A survey of the literature reveals that researchers have studied dielectric properties of PVA/PVAc-PVP blend films filled with different inorganic salts (solid polymeric electrolytes) [1]. Recently, many researchers have studied the structural and electrical (including dielectric) properties of the PVA-PVP blend doped with an inorganic salt in order to fabricate various devices [2-4]. Electrical impedance study on PVA-PVP complexed with sodium chloride $(\mathrm{NaCl})$ has already been performed [5]; this study revealed that there is an enhancement in electrical conductivity when $15 \mathrm{wt} \%$ (filler level) of $\mathrm{NaCl}$ is incorporated into the host PVA-PVP blend, and therefore, this particular material is suitable for battery application. PVA-PVP polymer nanocomposites incorporated with graphene oxide were synthesized [6]; the dielectric properties of these materials showed promising characteristics in order to fabricate batteries. Characterization of ammonium thiocyanate complexed with PVA-PVP has revealed an increase in the mobility of charge carriers; this enhances the electrical conductivity of the composite, as seen from the Cole-Cole plot [7]. A literature survey also reveals that magnesium ion conducting, magnesium chlorate $\left(\mathrm{Mg}\left(\mathrm{ClO}_{4}\right)_{2}\right)$-doped PVA-PVP blend polymer electrolyte has been synthesized; the ionic conductivity as well as dielectric behaviour of this material has been studied using AC impedance spectroscopy [8]. Dielectric study of un-doped and doped polymeric systems is an active field of research [9-12].

In the present study, cadmium chloride monohydrate $\left(\mathrm{CdCl}_{2} \cdot \mathrm{H}_{2} \mathrm{O}\right)$ has been chosen as a dopant. $\mathrm{CdCl}_{2} \cdot \mathrm{H}_{2} \mathrm{O}$ is a crystalline, divalent inorganic salt, which has many applications [13]. $\mathrm{CdCl}_{2}$ is a hygroscopic compound comprising cadmium $(\mathrm{Cd})$ and chlorine $(\mathrm{Cl})$, which is highly soluble in water. It is used in the preparation of fungicides, photocopying, dyeing (printing textiles), metal finishing baths and electroplating. Cd has a significant neutron absorption cross-section, and is useful as a neutron shielding material. Hence, in order to study the effect of doping on PVA-PVP blend films, $\mathrm{CdCl}_{2}$ is chosen as a dopant. PVA and PVA-PVP composites doped with $\mathrm{CdCl}_{2}$ have been studied earlier [14,15]. In the work presented here, the effects of variation in temperature and frequency on motion of charge carriers in the $\mathrm{CdCl}_{2}$-doped PVA/PVAc-PVP blend have been studied, using dielectric relaxation spectroscopy (DRS). This study enables an understanding of relaxation processes taking place in the polymeric material, due to micro-structural modifications caused 
by addition of a dopant [16-21]. Dielectric constant and dielectric loss are crucial parameters, which are useful in order to design devices (using doped polymeric materials), as they affect microscopic processes, for example, the relaxation of ions which occur in a material in the presence of an applied AC field [22,23]. The scanning electron microscope (SEM) image of the $10.2 \mathrm{wt} \%$ (doping level (DL)) $\mathrm{CdCl}_{2}$-doped PVA/PVAc-PVP film revealed formation of micro-globules of the dopant surrounded by polymeric molecules [24]. Due to its interesting microstructure, this particular sample (10.2 wt \% DL) was used in the present study, for a study of dielectric relaxation processes. For comparison purposes, the dielectric study of un-doped PVA/PVAc-PVP blend films $(0.0 \mathrm{wt} \% \mathrm{DL})$ was also performed, relative to change in frequency of an applied alternating signal, as well as change in temperature of the sample.

The un-doped and inorganic salt-doped polymeric blend samples were subjected to a detailed experimental investigation in order to determine their dielectric parameters, namely, tangent loss, dielectric loss, permittivity, bulk resistance and dielectric modulus, at different temperatures and frequencies. Three different relaxation processes, namely, alpha $(\alpha)$, beta $(\beta)$ and gamma $(\gamma)$ relaxation processes are found in semicrystalline polymeric materials, in the decreasing order of temperature; $\alpha$ - and $\beta$-relaxation processes are attributed to the amorphous and crystalline phases of polymers, respectively, and the $\gamma$-relaxation process is due to the localized motions of chains and branches associated with the amorphous phase $[21,25,26]$. The $\alpha$-relaxation is situated at the temperature of glass-rubber transition $\left(T_{\mathrm{g}}\right)$, and its value increases with an increase in amorphousness of the material $[27,28]$. Frequency and temperature dependent study of dielectric parameters is essential in order to understand the microstructure of polymers [29,30]. In dielectric studies on materials, two types of losses are expected; one is the conduction loss due to motion of charge carriers, and the other is dielectric loss, which involves the rotational and vibration motion of molecules and ions. The classical picture of dielectric relaxation in a fluid like medium (having a single relaxation time) is given by Debye theory [31], which is valid for non-interacting dipoles. The complex permittivity $\left(\varepsilon^{*}\right)$ is given by equation (1):

$$
\varepsilon^{*}=\varepsilon_{\infty}+\frac{\varepsilon_{0}-\varepsilon_{\infty}}{1+i \omega \tau}
$$

In equation (1), $\varepsilon_{0}$ is the dielectric constant at low frequency, $\varepsilon_{\infty}$ is the dielectric constant at high frequency, $\omega$ is the angular frequency, $i^{2}=-1$ and $\tau$ is the relaxation time.

Real and imaginary parts of the dielectric constant are given by equations ( 2 and 3 ):

$$
\begin{aligned}
\varepsilon^{\prime} & =\varepsilon_{\infty}+\frac{\varepsilon_{0}-\varepsilon_{\infty}}{1+\omega^{2} \tau^{2}} \\
\varepsilon^{\prime \prime} & =\left(\frac{\varepsilon_{0}-\varepsilon_{\infty}}{1+\omega^{2} \tau^{2}}\right) \omega \tau .
\end{aligned}
$$

Polymeric materials usually do not obey Debye theory. Therefore, Cole [32] modified equation (1) for various relaxation processes in these materials, which has been expressed in terms of an empirical parameter $\alpha$ (see equation (4)):

$$
\varepsilon^{*}-\varepsilon_{\infty}=\frac{\varepsilon_{0}-\varepsilon_{\infty}}{1+(i \omega \tau)^{1-\alpha}} .
$$

In equation (4), $\alpha$ is an empirical parameter whose value lies between 0 and 1 . It denotes the angle of deviation of the circular arc from the real axis in the Cole-Cole plot, a plot of $-Z \sin \theta$ vs. $Z \cos \theta$. In equation (4), $Z$ is the value of impedance and $\theta$ is the phase angle.

In the present work, using a personal computer (PC) interfaced precision LCR meter (details of which are given in section 2 of this paper), the values of impedance $(Z)$ and phase angle $(\theta)$ between the applied AC field and generated current were experimentally determined (measured). Negative values of $\theta$ were obtained for all samples, which implies a capacitive action in the circuit. Resistance $\left(R_{\mathrm{s}}\right)$ and reactance $\left(X_{\mathrm{s}}\right)$, the real $\left(Z^{\prime}\right)$ and imaginary $\left(Z^{\prime \prime}\right)$ parts of the impedance plot (Cole-Cole plot) have been calculated from the measured values of $Z$ and $\theta$. For parallel (equivalent) circuit, dissipation factor (or tangent loss) has been calculated by using the relation $D=\tan \delta$, where $\delta=(90-\theta)$. For a parallel plate capacitor formed by the sample sandwiched between two metal electrodes, the dielectric constant $\left(\varepsilon^{\prime}\right)$ and dielectric loss $\left(\varepsilon^{\prime \prime}\right)$ were calculated using equations (5 and 6$)$, respectively. Capacitance $(C)$ was calculated using equation (7):

$$
\begin{aligned}
\varepsilon^{\prime} & =\frac{C d}{\varepsilon_{0} A} \\
\varepsilon^{\prime \prime} & =\varepsilon^{\prime} \tan \delta \\
C & =\frac{\cos \theta}{Z \omega \tan \delta} .
\end{aligned}
$$

In equations (5 and 7), $C=C_{\mathrm{p}}$ is the capacitance of the sample (corresponding to the parallel equivalent circuit), $\omega$ is the angular frequency (note that $\omega=2 \pi f$, where $f$ is the linear frequency), $A$ is the area of the sample, $d$ is the thickness of the sample and $\varepsilon_{0}$ is the permittivity of free space $\left(\varepsilon_{0}=\right.$ $\left.8.854 \times 10^{-12} \mathrm{~F} \mathrm{~m}^{-1}\right)$. The AC electrical conductivity $(\sigma)$ is a function of angular frequency $(\omega)$. It has been calculated using equation (8):

$$
\sigma=\omega \varepsilon_{0} \varepsilon^{\prime \prime}
$$

\section{Experimental}

Semi-crystalline PVA/PVAc $\quad(85 \% \quad$ PVA:15\% PVAc; incompletely hydrolysed PVAc, having a molecular weight 140,000), amorphous PVP (molecular weight: 50,000) and $\mathrm{CdCl}_{2} \cdot \mathrm{H}_{2} \mathrm{O}$ were purchased from HiMedia Laboratories Pvt. Ltd, Mumbai. Here, it is important to note that, as PVA 
used for sample preparation is not completely hydrolysed, the abbreviation PVA/PVAc is used, instead of PVA. In order to prepare the un-doped (pure or neat) PVA/PVAc-PVP blend films, the aqueous solution containing $2 \mathrm{~g}$ each of thoroughly mixed PVA/PVAc granules and PVP powder was poured into a clean, dry glass Petri dish, for solution casting. The aqueous mixture was dried at $40^{\circ} \mathrm{C}$ in an air cooled, temperature controlled oven for several days, after which the translucent film of PVA/PVAc-PVP was peeled off from the glass substrate and stored under a dry atmosphere. In order to prepare the $\mathrm{CdCl}_{2}$-doped PVA/PVAc-PVP blend films, the following procedure has been adopted. Aqueous solutions of the PVA/PVAc-PVP blend were prepared in several glass beakers, by taking PVA/PVAc and PVP in equal proportion by weight and dissolving them in double distilled water. The standard solution of $\mathrm{CdCl}_{2} \cdot \mathrm{H}_{2} \mathrm{O}$ is prepared by dissolving it in double distilled water, and then, measured volumes of the standard solution were added to aqueous solution of the PVA/PVAc-PVP blend taken in different beakers, in order to obtain $\mathrm{CdCl}_{2}$-doped PVA/PVAc-PVP solutions with different concentrations of the dopant $\left(\mathrm{CdCl}_{2}\right)$. The aqueous solutions of the doped PVA/PVAc-PVP blend were then poured into properly labelled glass Petri dishes. An air cooled, temperature controlled oven maintained at $40^{\circ} \mathrm{C}$ was used to dry the samples. After drying, the films were peeled off from the glass substrate, carefully labelled and stored in a desiccator. Later, the films of $\mathrm{CdCl}_{2}$-doped PVA/PVAc-PVP blend were peeled off from the glass substrate, and stored in a desiccator.

In order to understand the capacitive action of $\mathrm{CdCl}_{2}$-doped PVA/PVAc-PVP blend films, dielectric measurements have been done using a precision LCR meter, GWINSTEK LCR821 , a research grade apparatus from Good Will Instruments Co. Ltd., Taiwan. The dielectric studies were performed by varying the frequency from $12 \mathrm{~Hz}$ up to $200 \mathrm{kHz}$, at different set temperatures (using a PID controlled furnace, accuracy of $0.1^{\circ} \mathrm{C}$ ). The values of impedance $(Z)$ and phase angle $(\theta)$ between the applied alternating field and generated current were experimentally determined at different frequencies and temperatures. The measurements using the LCR meter were done in the most precise (slow) mode of measurement. The other dielectric parameters were then determined, using standard formulae. The sample was placed between the metal electrodes (stainless steel and aluminium), held together by pressure contact.

\section{Results and discussion}

\subsection{Frequency dependence}

3.1a Bulk resistance: The impedance plots or Cole-Cole plots for $0.0 \mathrm{wt} \%$ (un-doped PVA/PVAc-PVP blend) and 10.2 wt\% (DL) $\mathrm{CdCl}_{2}$-doped PVA/PVAc-PVP blend films are shown in figure $1 \mathrm{a}$ and $\mathrm{b}$, respectively. Figure 1a shows two different regions, a linear region (spike) in the low frequency regime which is due to the two electrodes (between which the sample was sandwiched), i.e., electrode-electrolyte interface, and an elliptical region in the higher frequency, which is due to ion migration in the polymer matrix (which is a bulk effect). The data points can be fitted to form a part of an ellipse rather than a semi-circle, which reflects nonconformation to Debye description. An equivalent circuit for these two regions is shown in figure 1d. Figure 1e shows three regions: two ellipses can be fit to the data points; these are attributed to the bulk and grain boundaries in the sample, respectively, followed by a slanted spike which is attributed to the electrode-electrolyte effect. The corresponding equivalent circuit is shown as an inset in figure 1e. The $x$-axis intersection of this ellipse (on the real axis), which corresponds to grain boundaries, is larger when compared with that due to the bulk resistance; the corresponding resistance is denoted as $R_{3}$ (where $R_{3}=R_{\mathrm{gb}}=104.3 \mathrm{k} \Omega$ ), the resistance due to the grain interior of the sample, denoted as $R_{2}$ (where $R_{2}=R_{\mathrm{b}}=17.36 \mathrm{k} \Omega$ ). These values of resistances ( $R_{2}$ and $R_{3}$ ) have been obtained by fitting the impedance data using ZSimpWin software; the fitted values along with the equivalent circuit are shown in the inset in figure $1 \mathrm{~d}$ and $\mathrm{e}$. In the equivalent circuit, $R$ represents resistance, $C$ is the capacitance and $Q$ represents the constant phase element (CPE). This reveals that the grain boundaries (crystallites) are the highly resistive sites for the ion movement. The reduction in the values of bulk resistance $\left(R_{\mathrm{b}}\right)$ and the resistance of grain boundaries $\left(R_{\mathrm{gb}}\right)$ with temperature indicates thermally activated ion hopping via conducting pathways (for example, free volume in the amorphous regions and defects in the crystalline regions of the sample). In pure (0.0 wt $\%$ DL) PVA/PVAc-PVP blend films, ions from $>\mathrm{C}=\mathrm{O}, \mathrm{N}-\mathrm{H}$ and $\mathrm{OH}$ (functional groups in the polymers) involve in the electrical conduction process, whereas in $\mathrm{CdCl}_{2}$-doped PVA/PVAcPVP blend films, in addition to ions from the polymer side groups, dopant ions $\left(\mathrm{Cd}^{2+}\right.$ and $\left.\mathrm{Cl}^{-}\right)$are also responsible for charge transport. There could be a hopping mechanism from $\mathrm{CdCl}_{2}$ to $\mathrm{CdCl}_{2}$ and migration through the polymer backbone to $\mathrm{CdCl}_{2}$ as well. In an ideal case, at lower frequencies, the Cole-Cole plot is expected to be a straight line parallel to the imaginary $\left(Z^{\prime \prime}\right)$ axis, but the actual plot obtained is shown in figure $1 \mathrm{a}$ and $\mathrm{b}$.

The Cole-Cole plots were studied at different set temperatures, from 303 up to $373 \mathrm{~K}$, at every $10 \mathrm{~K}$ temperature difference. From the Cole-Cole plots, bulk resistance of the film was estimated for $0.0 \mathrm{wt} \%$ and $10.2 \mathrm{wt} \% \mathrm{DL}$ samples of $\mathrm{CdCl}_{2}$-doped PVA/PVAc-PVP blend. From figure 1a and $b$, it is noted that, for the $0.0 \mathrm{wt} \%$ DL sample, a single ellipse is observed. This is an indication that only one type of relaxation process is taking place in this material (un-doped PVA/PVAc-PVP film). For the $10.2 \mathrm{wt} \%$ DL film of $\mathrm{CdCl}_{2}$ doped PVA/PVAc-PVP blend, two ellipses are seen, which reveals that there are two modes of $\mathrm{AC}$ conduction. The bulk conductivity $\left(\sigma_{\mathrm{b}}\right)$ is calculated by using equation (9):

$$
\sigma_{\mathrm{b}}=\frac{d}{R_{\mathrm{b}} \times A} .
$$



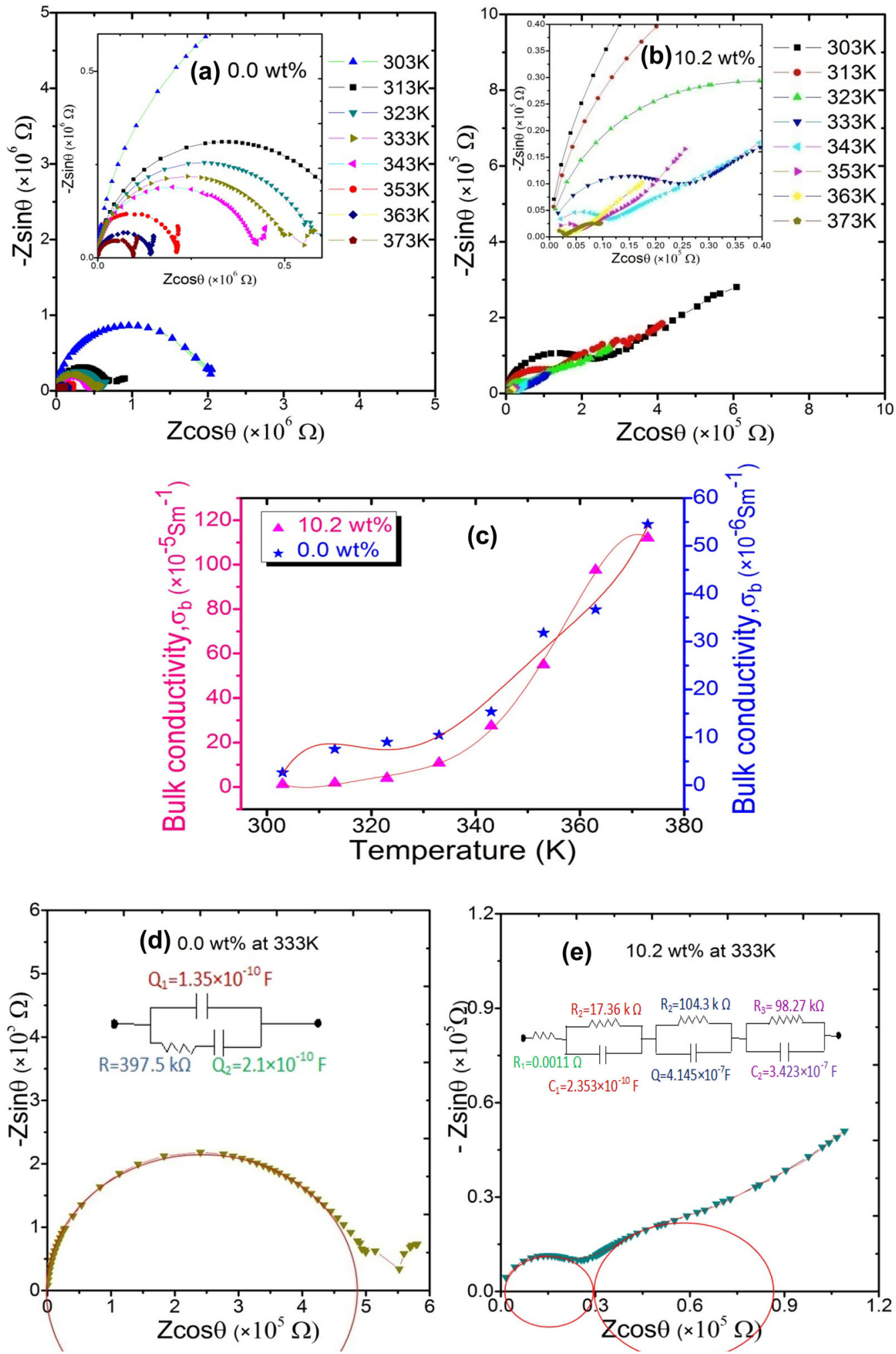

Figure 1. (a-c) Cole-Cole plot at different temperatures: (a) for $0.0 \mathrm{wt} \%$ and (b) $10.2 \mathrm{wt} \% \mathrm{CdCl}_{2}$-doped PVA/PVAc-PVP blend (inset: magnified part of the plot, at higher temperatures). (c) Variation of bulk conductivity with temperature at DLs of $0.0 \mathrm{wt} \%$ and $10.2 \mathrm{wt} \%$. (d, e) Impedance data and the equivalent circuits after fitting the data, the elliptical fit (rather than semi-circle) indicating non-conformation to a Debye description: (d) for $0.0 \mathrm{wt} \%$ and (e) for $10.2 \mathrm{wt} \% \mathrm{CdCl}_{2}$-doped PVA/PVAc-PVP blend films at $333 \mathrm{~K}$. 

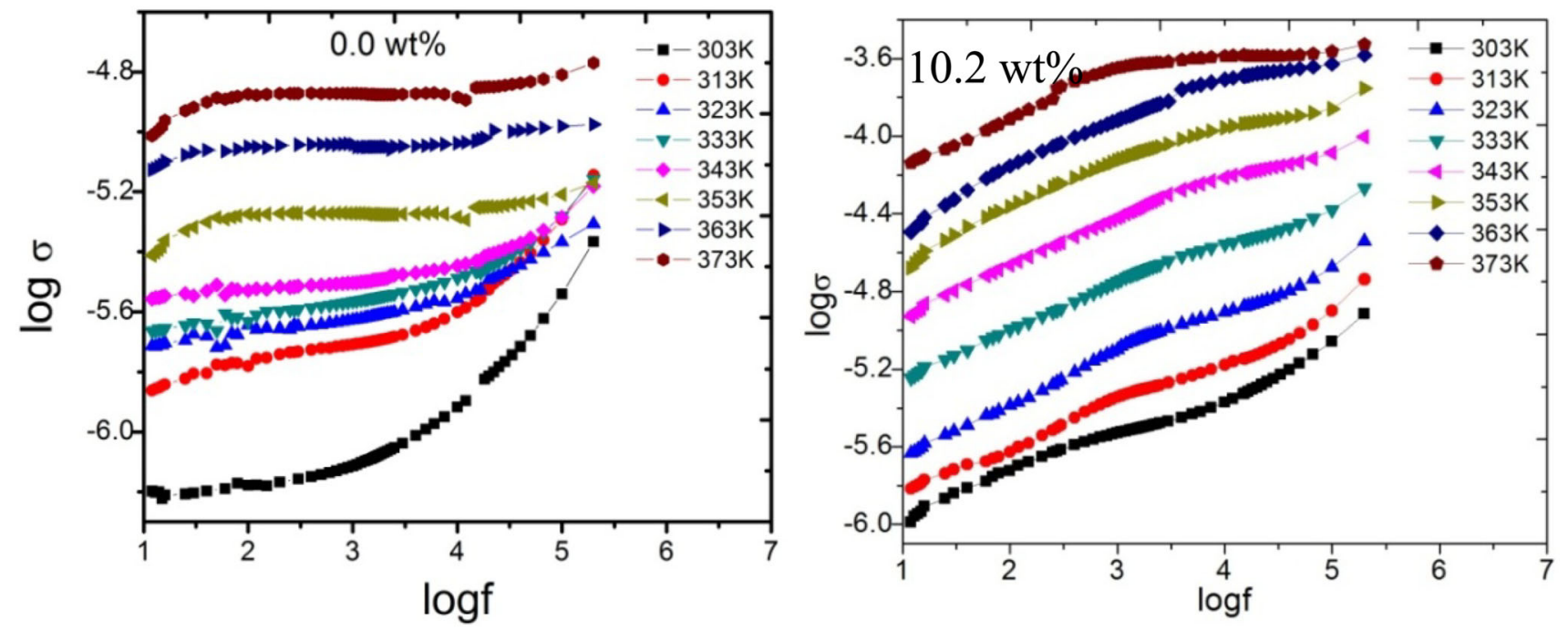

Figure 2. Frequency dependence of $\mathrm{AC}$ conductivity $(\sigma)$ studied at different temperatures, for $0.0 \mathrm{wt} \%$ and $10.2 \mathrm{wt} \% \mathrm{CdCl}_{2}$-doped PVA/PVAc-PVP blend films.

In equation (9), $d$ is the thickness of the sample, $R_{\mathrm{b}}$ is the bulk resistance and $A=\pi r^{2}$ is the area of each electrode. An enhancement in bulk conductivity (10 times more electrical conductivity) is observed for the $10.2 \mathrm{wt} \%$ DL sample when compared with the electrical conductivity of the un-doped (0.0 wt\% DL) sample, for temperatures set at particular values, from 303 up to $373 \mathrm{~K}$. From figure 1c, it can be seen that, although the values of bulk conductivity apparently seem to overlap, the order of magnitude is $10^{-5}$ (left side ordinate) for the sample with $10.2 \mathrm{wt} \% \mathrm{DL}$, whereas it is $10^{-6}$ (right side ordinate) in the case of pure PVA/PVAc-PVP blend ( $0.0 \mathrm{wt} \%$ DL). This indicates that the incorporation of $\mathrm{CdCl}_{2}$ into the PVA/PVAc-PVP blend films significantly improves electrical conductivity of the blend.

The reciprocal of bulk conductivity gives the value of bulk resistivity $\left(\rho_{\mathrm{b}}\right)$. The bulk resistance $\left(R_{\mathrm{b}}\right)$ of $\mathrm{CdCl}_{2}$-doped PVP blend films is estimated at different temperatures; the value where the fitted semicircle (in Cole-Cole plot) intersects the real axis $\left(Z^{\prime}\right)$ at different temperatures, which gives the value of $R_{\mathrm{b}}$ as illustrated in figure $1 \mathrm{~d}$ and e. The value of $R_{\mathrm{b}}$ decreases with an increase in temperature, due to enhancement of ion mobility in the polymeric material, and hence, there is an increase in bulk conductivity for both $0.0 \mathrm{wt} \%$ (pure) and $10.2 \mathrm{wt} \% \mathrm{CdCl}_{2}$-doped PVA/PVAc-PVP blend films with an increase in temperature (as shown in figure 1c). As the temperature is increased, segmental mobility of polymer molecules overcomes the hydrostatic force, and there is creation of additional free volume in the polymer matrix. Hence, an increase in ionic conductivity (and decrease in the bulk resistivity) is observed in these samples, at higher temperatures. A similar effect has been observed by other researchers, in various types of polymeric materials [33-38].

3.1b AC conductivity studies: Figure 2 shows the frequency dependence of AC conductivity for un-doped and $10.2 \mathrm{wt} \%$
$\mathrm{CdCl}_{2}$-doped PVA/PVAc-PVP blend films, at various fixed temperatures. As temperature increases, the $\mathrm{AC}$ conductivity of pure $(0.0 \mathrm{wt} \% \mathrm{DL})$ and $10.2 \mathrm{wt} \% \mathrm{DL} \mathrm{CdCl}_{2}$-doped PVA/PVAc-PVP blend films increases due to increased segmental mobility and higher free volume in the polymeric film, which aids movement of ions. The frequency dependence of AC conductivity has been studied in the frequency range varying from $12 \mathrm{~Hz}$ up to $200 \mathrm{kHz}$, at different fixed temperatures (as shown in figure 2). It is important to note that, in figure $2 \mathrm{a}$ and $\mathrm{b}$, the $x$-axis (abscissa) values are the logarithm of the applied signal frequencies, and hence the abscissa scale is from 1 to 7 (instead of $12 \mathrm{~Hz}$ to $200 \mathrm{kHz}$ ); this has been done for the better visualization of values in the plot. The formula given in equation (8) has been used to calculate the value of $\mathrm{AC}$ Conductivity $(\sigma)$. Two different regions have been observed: one corresponding to DC conductivity $\left(\sigma_{\mathrm{DC}}\right)$ is observed in the lower frequency region (from 12 up to $300 \mathrm{~Hz}$ ), which is attributed to space charge polarization at the electrodeelectrolyte interface, whereas the other region is observed in the higher frequency regime (from $400 \mathrm{~Hz}$ up to $200 \mathrm{kHz}$ ), which is attributed to ion migration under an influence of the applied AC field. In the lower frequency region, the high energy barriers are due to longer relaxation time of charge carriers. Another perception is that, due to more number of ions which accumulate on the electrode, there are less number of charge carriers available for transportation (charge transport), and therefore, the AC conductivity is lower at low frequencies. In un-doped (0.0 wt \% DL) PVA/PVAc-PVP blend films, ions from $>\mathrm{C}=\mathrm{O}, \mathrm{N}-\mathrm{H}$ and $\mathrm{OH}$ (functional groups in the polymers) are involved in the electrical conduction, whereas in $\mathrm{CdCl}_{2}$-doped PVA/PVAc-PVP blend films, in addition to ions of polymer side groups, dopant ions $\left(\mathrm{Cd}^{2+}\right.$ and $\left.\mathrm{Cl}^{-}\right)$also contribute to the charge transport. The charge accumulation at the electrode-electrolyte interface indicates non-Debye nature of conduction in the sample. This is reflected in a lower value 
Table 1. Parameters extracted from dielectric measurement data (at different set temperatures), for the un-doped (0.0 wt \% DL) PVA/PVAc-PVP blend film and the $10.2 \mathrm{wt} \% \mathrm{DL} \mathrm{CdCl}_{2}$-doped PVA/PVAc-PVP blend film.

\begin{tabular}{lccccc}
\hline Temperature (K) & $s$ & $\tan \delta_{\max }$ & $\log f_{\max }$ & Relaxation time $\left(\times 10^{-3} \mathrm{~s}\right)$ & $\sigma_{\mathrm{b}}\left(\times 10^{-5} \mathrm{~S} \mathrm{~m}^{-1}\right)$ \\
\hline \multicolumn{7}{l}{ For 0.0 wt\% DL (un-doped) PVA/PVAc-PVP blend film } & & \\
303 & $0.519 \pm 0.023$ & 7.321 & 1.368 & 6.799 & 0.266 \\
313 & $0.431 \pm 0.006$ & 6.358 & 1.551 & 4.461 & 0.756 \\
323 & $0.380 \pm 0.001$ & 11.68 & 1.887 & 2.058 & 0.902 \\
333 & $0.378 \pm 0.026$ & 8.264 & 2.070 & 1.350 & 1.051 \\
343 & $0.216 \pm 0.010$ & 9.373 & 2.172 & 1.068 & 1.537 \\
353 & $0.108 \pm 0.005$ & 13.69 & 2.417 & 0.607 & 3.181 \\
363 & $0.082 \pm 0.001$ & 13.69 & 2.783 & 0.261 & 3.667 \\
373 & $0.062 \pm 0.003$ & 14.11 & 2.600 & 0.399 & 5.453 \\
For 10.2 wt\% DL CdCl - doped PVA PVAc-PVP blend film & & 1.15 \\
303 & $0.501 \pm 0.031$ & 2.72 & 2.44 & 0.578 & 1.76 \\
313 & $0.492 \pm 0.034$ & 2.04 & 3.02 & 0.152 & 3.93 \\
323 & $0.418 \pm 0.030$ & 2.23 & 3.26 & 0.087 & 10.80 \\
333 & $0.332 \pm 0.028$ & 2.65 & 3.60 & 0.039 & 27.49 \\
343 & $0.241 \pm 0.028$ & 3.39 & 3.79 & 0.026 & 54.97 \\
353 & $0.209 \pm 0.021$ & 4.00 & 4.04 & 0.014 & 97.53 \\
363 & $0.131 \pm 0.016$ & 5.71 & 4.09 & 0.013 & 111.90 \\
373 & $0.122 \pm 0.011$ & 9.36 & 3.90 & 0.020 & \\
\hline
\end{tabular}

for AC conductivity of the sample, whereas, the increment of $\mathrm{AC}$ conductivity in the high-frequency region is due to the increase in the number of charge carriers, corresponding to a lower energy barrier. The equation for total conductivity $(\sigma)$ can be expressed in terms of Jonscher's universal power law (see equations (10 and 11), which follows) [39]:

$$
\begin{aligned}
& \sigma=\sigma_{\mathrm{DC}}+\sigma_{\mathrm{AC}} \\
& \sigma=\sigma_{\mathrm{DC}}+A \omega^{\mathrm{s}} .
\end{aligned}
$$

In equation (11), $A$ is a temperature dependent parameter and $s$ is a temperature dependent frequency exponent. According to Funke's jump relaxation phenomenon [40], the value of $s$ is given by equation (12):

$$
s=\frac{\text { Back hop rate }}{\text { Site relaxation time }} \text {. }
$$

The backward hopping is slower than site relaxation, for $s<1$. If $s$ exceeds 1 , backward hopping is faster than site relaxation [41]. The value of $s$ is less than 1 for PVA/PVAcPVP blend films doped with $\mathrm{CdCl}_{2}$ (the values of the dielectric parameters are listed in table 1), as can be calculated from the slope (of linear fit) of $\log \sigma$ vs. $\log f$ plot, by considering data in the higher frequency region (figure 2). It is therefore concluded that, site relaxation takes place at a faster rate when compared with backward hopping.

By rearranging equations (8 and 11), a relation between $\ln \varepsilon^{\prime \prime}$ and $\ln \omega$ is obtained, which is called as Maxwell-Wagner formula, for heterogeneous media (see equation (13)):

$$
\ln \varepsilon^{\prime \prime}=\ln \left(\frac{A}{\varepsilon_{0}}\right)+(s-1) \ln \omega .
$$

Equation (13) enables an understanding of the site relaxation (hopping) rate $s$. For $0<s<0.7$, the dielectric phenomenon is explained using a correlated barrier hopping (CBH) model, and for $0 \leq s<0.7$, the dielectric phenomenon is explained using a quantum mechanical tunnelling (QMT) model. According to the $\mathrm{CBH}$ model, charge carriers hop between two localized sites of barrier potential $\left(W_{\mathrm{h}}\right)$, which is determined using equation (14):

$$
W_{\mathrm{h}}=\frac{6 k_{\mathrm{B}} T}{(1-s)} \text {. }
$$

In equation (14), $k_{\mathrm{B}}=8.615 \times 10^{-5} \mathrm{eV} \mathrm{K}^{-1}$ (the Boltzmann constant) and $T$ is the absolute temperature. According to the QMT model, charge carriers move between the localized states with the assistance of phonons near the Fermi level. Value of $s$ is calculated from the slope of the linear fit, in the plot of $\ln \varepsilon^{\prime \prime} v s . \ln \omega$ (shown in figure 3) in the complete frequency range under study.

The calculated value of $s$ (see the values listed in table 2) implies that the CBH mechanism (rather than the QMT mechanism) should be used to explain dispersion behaviour of the dielectric properties of $\mathrm{CdCl}_{2}$-doped PVA/PVAc-PVP blend films. The decrease in the value of $s$ and increase in the barrier height with an increase in temperature indicates that continuous forward and backward hopping of ions between the localized sites of the polymer matrix creates a barrier potential. Hence, an amount of energy equal to $W_{\mathrm{h}}$ is necessary for charge carriers to hop from one site to another.

3.1c Dielectric constant and dielectric loss: Figure 4a-d shows the variation of dielectric constant $\left(\varepsilon^{\prime}\right)$ and dielectric 

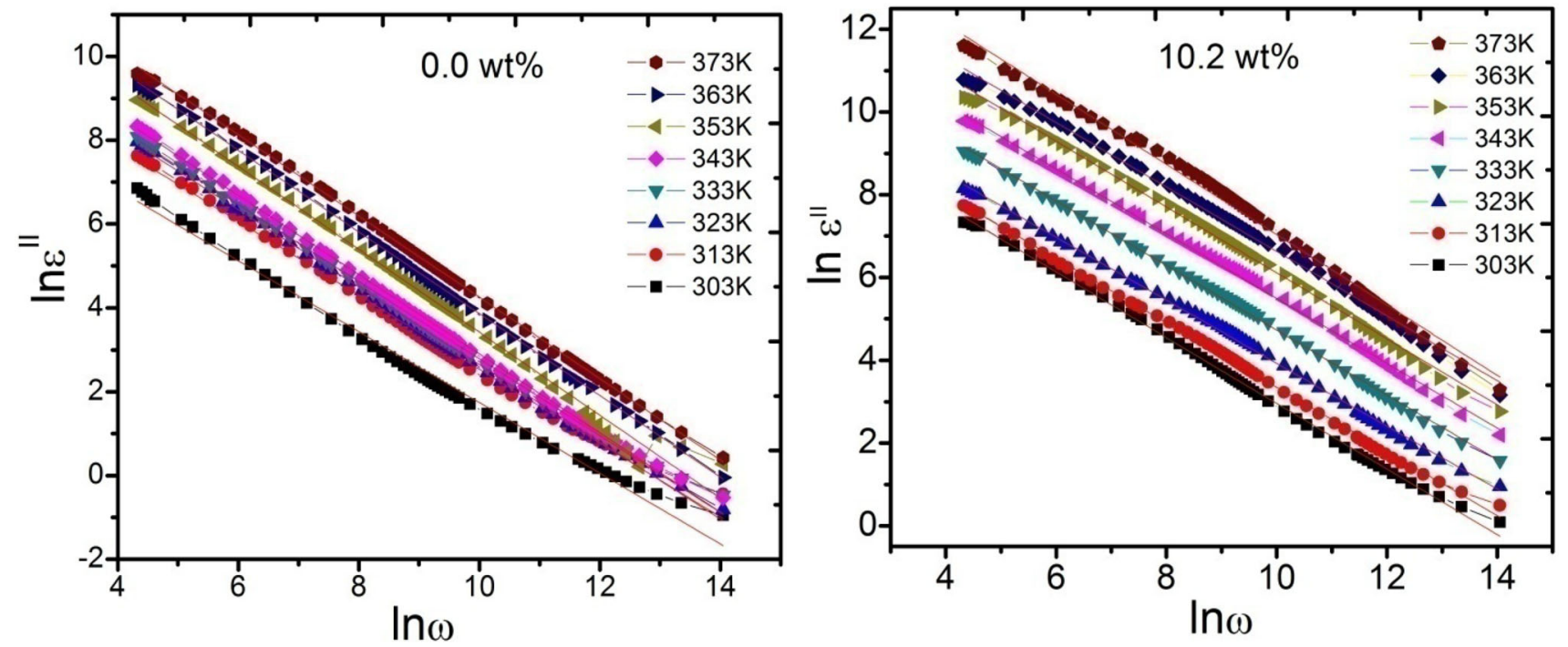

Figure 3. The plot of $\ln \varepsilon^{\prime \prime} v s$. $\ln \omega$, for the un-doped PVA/PVAc-PVP blend and $10.2 \mathrm{wt} \% \mathrm{DL} \mathrm{CdCl}_{2}$ in the PVA/PVAc-PVP blend films.

Table 2. Dependence of $s$ and barrier potential $\left(W_{\mathrm{h}}\right)$ on the absolute temperature $(T)$, for pure and $10.2 \mathrm{wt} \% \mathrm{CdCl}_{2}$ in PVA/PVAc-PVP blend films.

\begin{tabular}{lccccc}
\hline & \multicolumn{2}{c}{$0.0 \mathrm{wt} \%$} & & \multicolumn{2}{c}{$10.2 \mathrm{wt} \%$} \\
\cline { 2 - 3 } \cline { 5 - 6 }$T(\mathrm{~K})$ & $s$ & $W_{\mathrm{h}}(\mathrm{eV})$ & & $s$ & $W_{\mathrm{h}}(\mathrm{eV})$ \\
\hline 303 & $0.130 \pm 0.009$ & $0.180 \pm 0.012$ & & $0.247 \pm 0.004$ & $0.208 \pm 0.003$ \\
313 & $0.104 \pm 0.005$ & $0.181 \pm 0.008$ & & $0.234 \pm 0.003$ & $0.211 \pm 0.003$ \\
323 & $0.077 \pm 0.004$ & $0.181 \pm 0.009$ & & $0.230 \pm 0.004$ & $0.217 \pm 0.004$ \\
333 & $0.062 \pm 0.004$ & $0.184 \pm 0.013$ & & $0.219 \pm 0.003$ & $0.220 \pm 0.003$ \\
343 & $0.055 \pm 0.004$ & $0.188 \pm 0.013$ & & $0.198 \pm 0.004$ & $0.221 \pm 0.004$ \\
353 & $0.040 \pm 0.003$ & $0.190 \pm 0.015$ & & $0.186 \pm 0.005$ & $0.224 \pm 0.005$ \\
363 & $0.025 \pm 0.002$ & $0.193 \pm 0.015$ & & $0.169 \pm 0.005$ & $0.226 \pm 0.007$ \\
373 & $0.030 \pm 0.003$ & $0.199 \pm 0.019$ & & $0.151 \pm 0.009$ & $0.227 \pm 0.013$ \\
\hline
\end{tabular}

loss $\left(\varepsilon^{\prime \prime}\right)$ with frequency, at various fixed temperatures, for samples with $0.0 \mathrm{wt} \%$ and $10.2 \mathrm{wt} \% \mathrm{DL}$ of $\mathrm{CdCl}_{2}$ in the PVA/PVAc-PVP polymeric blend. Larger values of dielectric constant and dielectric loss are observed in the lower frequency range; the value of these parameters decreases with an increase in frequency of the applied alternating signal, becoming independent of frequency at higher frequencies.

With an increase in the temperature of the sample, there is a monotonic increase in the values of $\varepsilon^{\prime}$ and $\varepsilon^{\prime \prime}$, which implies that the orientation of dipoles at lower frequencies is facilitated at a higher temperature [42-44]. However, at higher frequencies, the dipoles are unable to orient themselves with the rapidly changing applied field direction. At higher frequency of the applied alternating signal, less polarization occurs in the sample due to accumulation of charges at the electrolyte-electrode interface. Hence, a reduction in the values of $\varepsilon^{\prime}$ and $\varepsilon^{\prime \prime}$ is observed with an increase in frequency. It can be noted that, the value of $\varepsilon^{\prime}$ and $\varepsilon^{\prime \prime}$ in the un-doped PVA/PVAc-PVP (0.0 wt $\%)$ sample is 10 times less than that for the $10.2 \mathrm{wt} \%$ sample. This is because, a larger number of mobile charge carriers are available in the $\mathrm{CdCl}_{2}$-doped PVA/PVAc-PVP blend (due to $\mathrm{Cd}^{2+}$ and $\mathrm{Cl}^{-}$ ions of the dopant), when compared with the un-doped PVA/PVAc-PVP blend. Sharp rise of the dielectric parameters $\left(\varepsilon^{\prime}\right.$ and $\left.\varepsilon^{\prime \prime}\right)$ in the lower frequency region also confirms the non-Debye nature of electrode polarization [45].

3.1d Tangent loss: The study of tangent loss of $\mathrm{CdCl}_{2}$-doped PVA/PVAc-PVP blend films with increase in temperature and with the variation in frequency (of applied alternating signal) gives an idea about energy lost when compared with energy stored per cycle of the alternating field. This ratio increases with increasing temperature. The tangent loss increases with an increase in the frequency of the applied alternating signal, and reaches a maximum value $\left(\tan \left(\delta_{\max }\right)\right)$ at a particular frequency $\left(f_{\max }\right)$, followed by a decrease at higher frequencies. When the temperature is set at a higher value, larger value of tangent loss (see figure 5a and c) is observed, and in addition, there is a shift in the peak position to a higher 

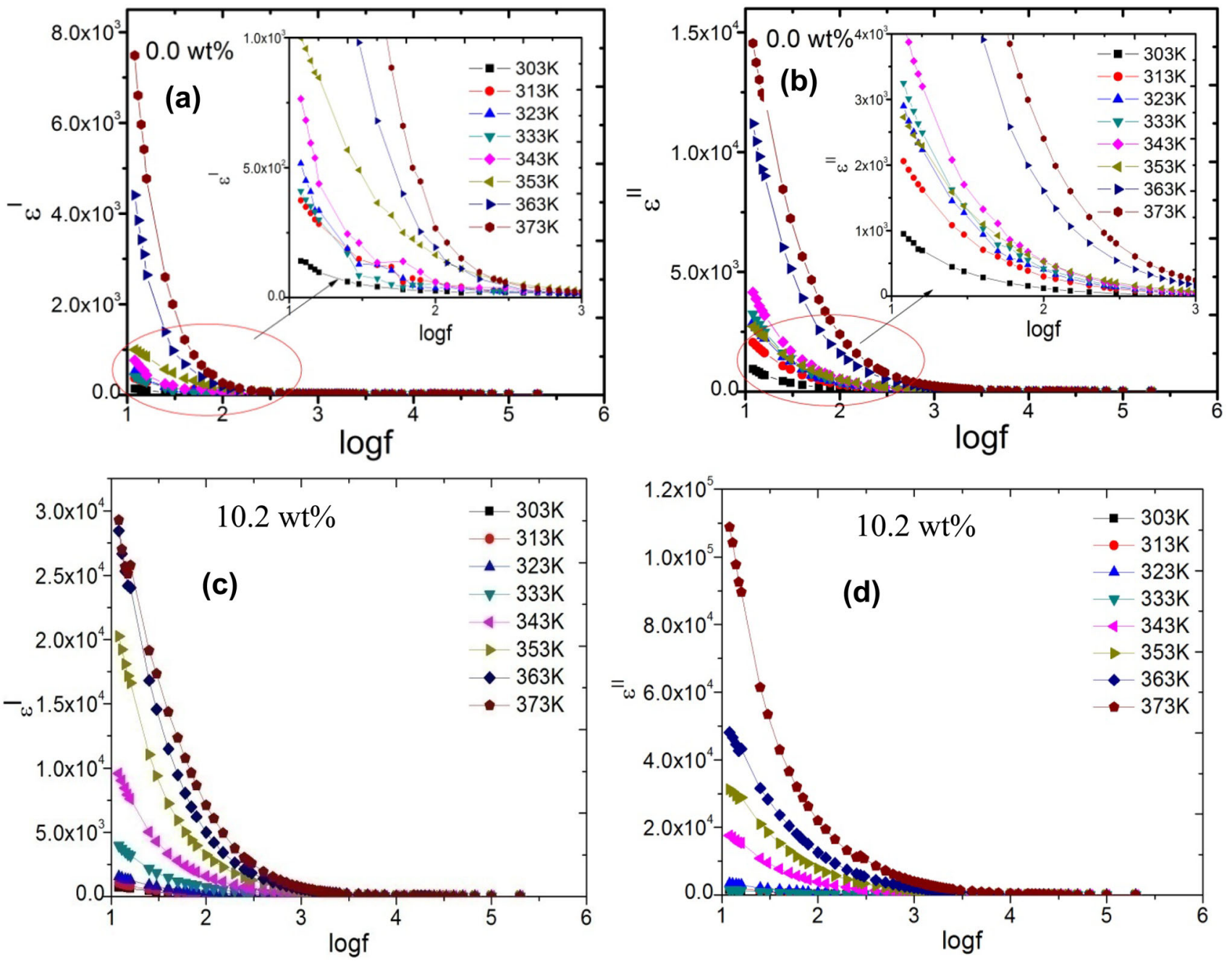

Figure 4. (a-d) The frequency dependence of dielectric constant $\left(\varepsilon^{\prime}\right)$ at different temperatures (a and $\mathbf{c}$ ); and the frequency dependence of dielectric loss $\left(\varepsilon^{\prime \prime}\right)$ at different temperatures (b and $\mathbf{d}$ ); for $0.0 \mathrm{wt} \%$ and $10.2 \mathrm{wt} \% \mathrm{CdCl}_{2}$-doped PVA/PVAc-PVP blend films. The insets show the magnified portion at lower temperature values.

value of frequency. The presence of maximum loss (peak) at lower frequency is due to charge carrier accumulation at the electrolyte-electrode interface. At higher frequencies, the periodic reversal of the electric field occurs so fast that, there is no excess ion diffusion in the direction of the field. This implies that there is thermally activated motion of the more polar parts of this sample, a thermally activated relaxation process $[46,47]$. These changes are clearly seen in the normalized plot of tangent loss vs. frequency (see figure $5 b$ and c). The normalized tangent loss spectra (see figure $5 \mathrm{~d}$ ) again confirm that the dielectric losses occur due to two regions, namely, grain interior (bulk) and grain boundary regions. At higher temperature, flexibility of the $\mathrm{CdCl}_{2}$-doped PVA/PVAc-PVP blend film increases, and hence, the orientation of dipoles is facilitated. Thus, larger value of dielectric loss is observed at higher temperature. These peaks have been observed below the melting temperature and near the glass transition $\left(T_{\mathrm{g}}\right)$ temperature, due to the orientation of dipoles and the $\alpha$-relaxation.
The peak frequency $\log \left(f_{\max }\right)$ can be described using the Arrhenius relation (see equation (15)):

$$
f_{\mathrm{p}}=f_{\mathrm{p} 0} \exp \left(-\frac{E_{\mathrm{A}}}{k_{\mathrm{B}} T}\right)
$$

In equation (15), $f_{\mathrm{p}}$ is peak frequency, $f_{\mathrm{p} 0}$ is a constant and $k_{\mathrm{B}}$ is the Boltzmann constant. The activation energy is obtained from the slope of the linear fit, in the linear region of the plot of $\ln f_{\mathrm{p}} v s$. reciprocal temperature. The activation energy $\left(E_{\mathrm{A}}\right)$ is found to be $0.56 \pm 0.04 \mathrm{eV}$, for films with $10.2 \mathrm{wt} \%$ DL of $\mathrm{CdCl}_{2}$ in the PVA/PVAc-PVP blend.

Relaxation time $(\tau)$ has been estimated using the relation given in equation (16):

$$
\tau=\frac{1}{2 \pi f_{\mathrm{p}}} .
$$



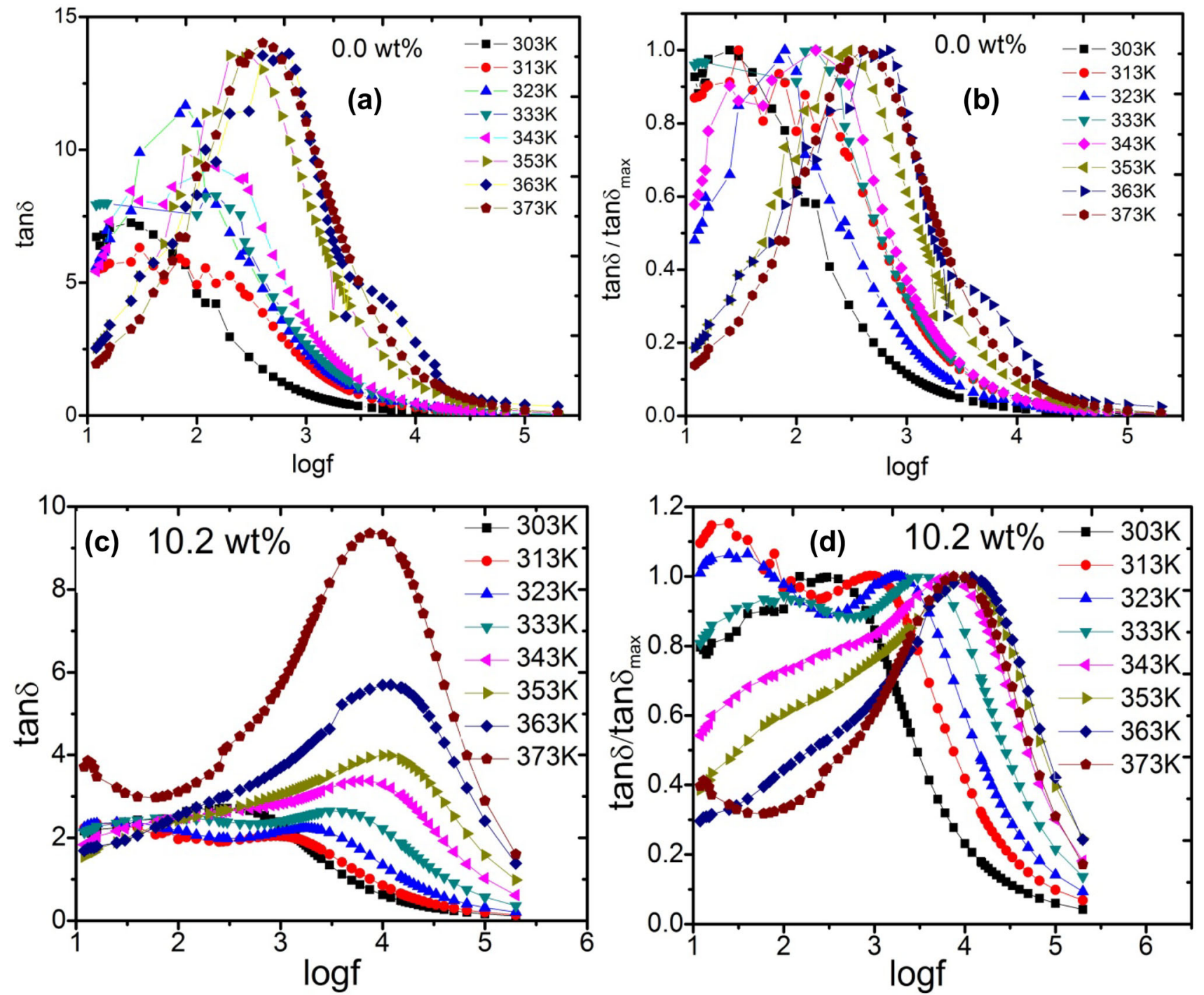

Figure 5. (a-d) Frequency dependent tangent loss ( $\tan \delta)$, (a) normalized tangent loss (b) at different temperatures for the un-doped $(0.0 \mathrm{wt} \% \mathrm{DL})$ polymeric blend; and frequency dependent tangent loss $(\tan \delta)$, (c) normalized tangent loss (d) at different temperatures for the $10.2 \mathrm{wt} \% \mathrm{CdCl}_{2}$-doped PVA/PVAc-PVP blend film.

The order of $\tau$ (refer to table 1) indicates involvement of dipoles in $\mathrm{AC}$ conduction. The decrease in relaxation time with increase in temperature indicates that $\mathrm{AC}$ conductivity of the $\mathrm{CdCl}_{2}$-doped PVA/PVAc-PVP blend samples increases at higher temperatures $[48,49]$.

3.1e Electric modulus: The dielectric spectra of the $\mathrm{CdCl}_{2}$-doped PVA/PVAc-PVP blend films were analysed in terms of complex electric modulus $M^{*}$ (using equation (17), where $\left.j^{2}=-1\right)$, which can be evaluated from its real $\left(M^{\prime}\right)$ and imaginary $\left(M^{\prime \prime}\right)$ parts, using the relations given in equations (18 and 19) [50-52]:

$$
M^{*}=\frac{1}{\varepsilon^{*}}=M^{\prime}+j M^{\prime \prime}
$$

$$
\begin{aligned}
& M^{\prime}=\frac{\varepsilon^{\prime}}{\varepsilon^{\prime 2}+\varepsilon^{\prime 2}} \\
& M^{\prime \prime}=\frac{\varepsilon^{\prime \prime}}{\varepsilon^{\prime 2}+\varepsilon^{\prime \prime 2}} .
\end{aligned}
$$

Figure 6a-d shows the variation of $M^{\prime}$ and $M^{\prime \prime}$ with the frequency, at various temperatures. The smaller value of $M^{\prime}$, which is observed at low frequencies, indicates the removal of electrode polarization. A decrease in $M^{\prime}$ values with increase in temperature is because of the expanded movement of large parts of molecular chains in the polymer. With an increase in temperature of the sample, large dipoles get oriented easily, and therefore, $M^{\prime}$ reduces at lower frequencies, whereas $\varepsilon^{\prime}$ increases. As the dipoles cannot orient at higher frequency, the effect of increased temperature becomes ineffective. 

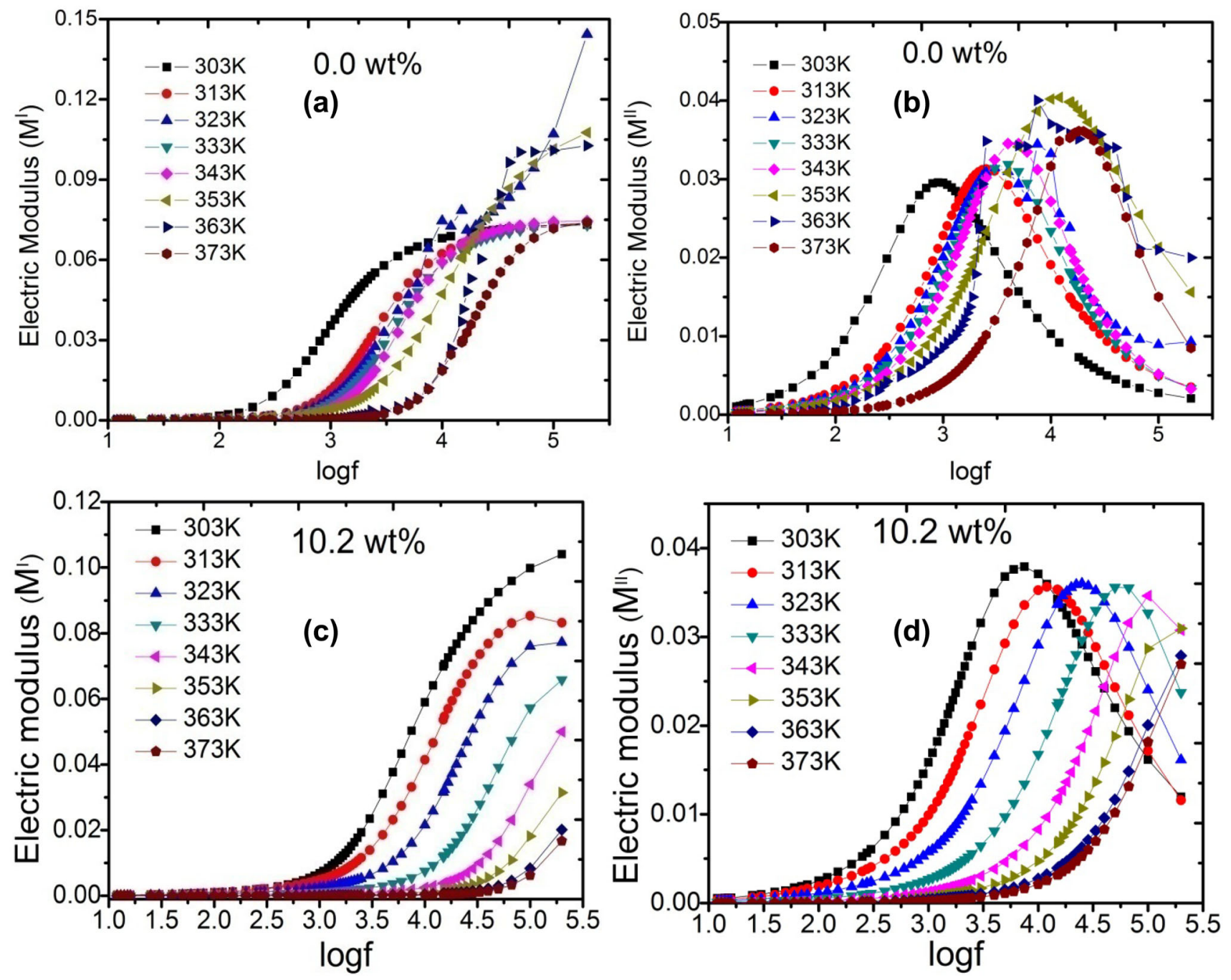

Figure 6. (a-d) Frequency dependence of electric modulus: (a and c) real part of electric modulus, $M^{\prime}$, and (b and d) imaginary part of electric modulus, $M^{\prime \prime}$, at different temperatures (varying from 303 to $373 \mathrm{~K}$ ), for 0.0 and $10.2 \mathrm{wt} \% \mathrm{CdCl}_{2}$-doped PVA/PVAc-PVP blend films.

The $M^{\prime \prime}$ spectrum (figure $6 \mathrm{~b}$ ) shows a peak, which is observed to shift towards higher frequency with an increase in temperature. Dielectric relaxation is a reorientation of dipoles in the polymer composite, and the existence of this process will be revealed by a peak in the $\varepsilon^{\prime \prime}$ spectrum. However, long range conduction process and dielectric relaxation are different phenomena. In a polymer electrolyte, during the movement of ions from one site to another, electric potential will get disturbed, forming a perturbed electric potential. This perturbation of potential will continue for the neighbouring ions, and hence, affects the conduction due to relaxation processes. No peaks have observed in the $\varepsilon^{\prime \prime}$ spectrum, but a peak is observed in the $M^{\prime \prime}$ spectrum. This is evidence for the conduction process being due to the movement of ions and polymer segmental motion. In the $\mathrm{CdCl}_{2}$-doped PVA/PVAcPVP blend films, the conduction process occurs due to charge migration, due to $\mathrm{Cd}^{2+}$ and $\mathrm{Cl}^{-}$ions of the dopant, $\mathrm{H}^{+}$and
$\mathrm{O}^{-}$ions of functional groups of PVA/PVAc and PVP (between the coordination sites), as well as segmental relaxation of the polymer chains.

\subsection{Temperature dependence}

3.2a AC conductivity: Variation of series resistance $\left(R_{\mathrm{S}}\right)$ of un-doped and $10.2 \mathrm{wt} \% \mathrm{CdCl}_{2}$-doped PVA/PVAc-PVP blend films, with reciprocal of absolute temperature is shown in figure $7 \mathrm{a}$ and $\mathrm{b}$, respectively. The variation of $\mathrm{AC}$ conductivity with temperature (which has been studied at different frequencies) is also shown (inset) in figure $7 \mathrm{a}$ and $\mathrm{b}$.

Activation energy $\left(E_{\mathrm{A}}\right)$ is determined at different frequencies, using the slope of the linear fit, considering the linear region of the plot of $\ln R_{\mathrm{S}} v s .1 / T$, with reference to equation (20). The values obtained for activation energy are listed in table 3 . There is a slight increase in AC conductivity 

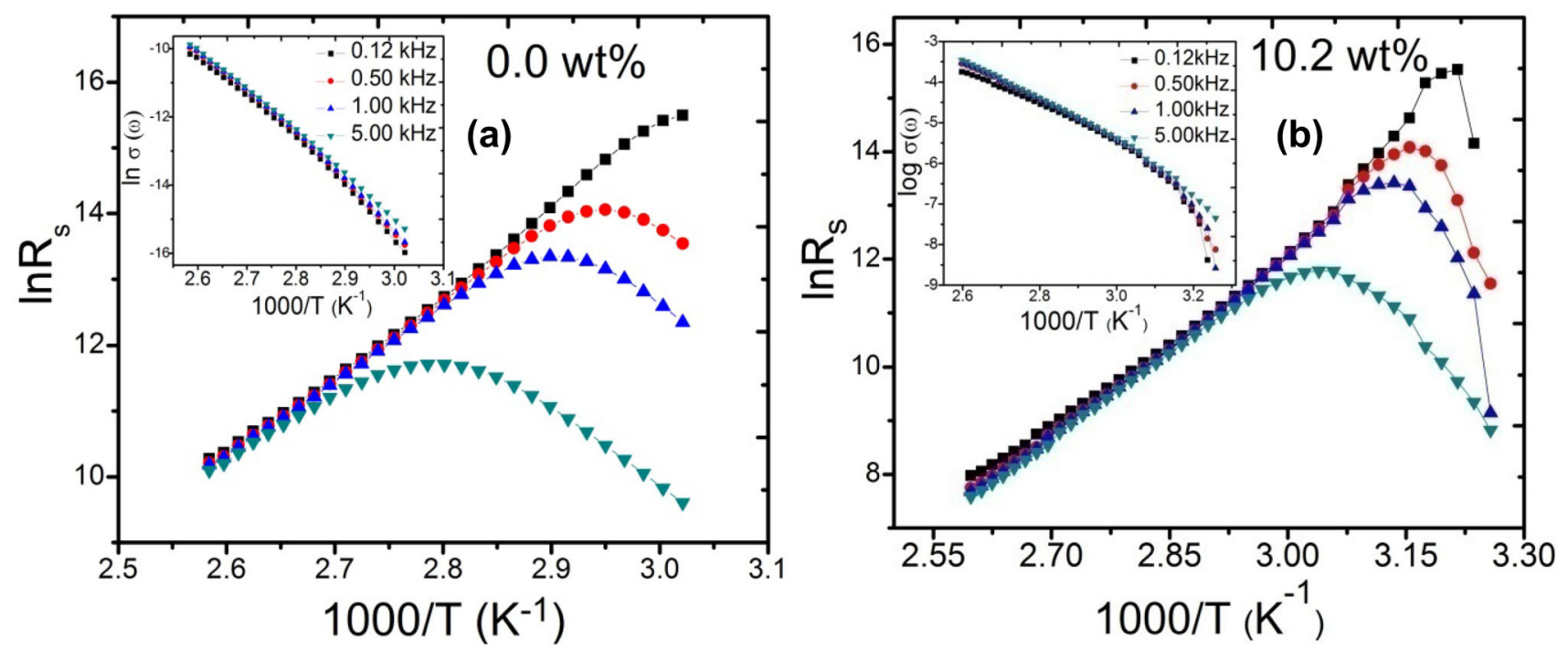

Figure 7. (a and b) Variation of $\ln \left(R_{\mathrm{S}}\right) v s$. reciprocal temperature $(1 / T)$ and the inset shows temperature dependent AC conductivity spectra at different set frequencies $(0.12,0.50,1.00$ and $5.00 \mathrm{kHz})$, for $10.2 \mathrm{wt} \% \mathrm{CdCl}_{2}$-doped PVA/PVAc-PVP blend films.

Table 3. Activation energy ( $E_{\mathrm{A}}$, expressed in $\left.\mathrm{eV}\right)$, for 0.0 and $10.2 \mathrm{wt} \% \mathrm{DL}$ of $\mathrm{CdCl}_{2}$ in the PVA/PVAc-PVP blend films, at different frequencies $(f)$.

\begin{tabular}{lcc}
\hline & $E_{\mathrm{A}}(\mathrm{eV})$ & $E_{\mathrm{A}}(\mathrm{eV})$ \\
$f(\mathrm{kHz})$ & $\mathrm{DL}=0.0 \mathrm{wt} \%$ & $\mathrm{DL}=10.2 \mathrm{wt} \%$ \\
\hline 0.12 & $1.018 \pm 0.010$ & $0.937 \pm 0.004$ \\
0.50 & $0.959 \pm 0.005$ & $0.933 \pm 0.005$ \\
1.00 & $0.887 \pm 0.006$ & $0.931 \pm 0.005$ \\
5.00 & $0.779 \pm 0.019$ & $0.905 \pm 0.004$ \\
\hline
\end{tabular}

$(\sigma)$ with frequency, and a decrease in the activation energy with an increase in frequency of the applied AC field.

$$
R_{\mathrm{s}}=R_{0} \exp \left(\frac{E_{\mathrm{A}}}{k_{\mathrm{B}} T}\right) .
$$

3.2b Dielectric constant and dielectric loss: The values of dielectric constant (see figure 8a) and dielectric loss (inset in figure $8 b$ ) are observed to be increasing with increase in temperature. It is observed that more dielectric loss occurs at higher temperatures, which is due to more number of possible rotational and vibrational modes at higher temperatures $[53,54]$. As observed in figure $8 \mathrm{a}$ and $\mathrm{b}$, the decrease in $\varepsilon^{\prime}$ and $\varepsilon^{\prime \prime}$ with frequency implies that dipoles are unable to orient themselves with the applied field at higher frequency, when compared with lower frequency. Therefore, there is more loss at lower frequency. The values of $\varepsilon^{\prime}$ and $\varepsilon^{\prime \prime}$ indicate that more number of dipoles are getting oriented at 10.2 wt\% DL of $\mathrm{CdCl}_{2}$ in the PVA/PVAc-PVP blend, when compared with the un-doped (0.0 wt $\%)$ PVA/PVAc-PVP blend sample. Hence, more dielectric loss has been observed for the $10.2 \mathrm{wt} \% \mathrm{CdCl}_{2}$-doped PVA/PVAc-PVP blend film.
The increase in the values of $\varepsilon^{\prime}$ and $\varepsilon^{\prime \prime}$ at higher temperature causes an increase in viscosity of the film. This improves friction of rotating dipoles and the degree of dipole orientation. During migration of dipoles, the charge carriers may be trapped in the dielectric, which produces distortions like lattice defects, free volumes (voids) and strains. This leads to more loss at higher temperature.

3.2c Tangent loss: The variation of tangent loss $(\tan \delta)$ with temperature (of sample) at various fixed frequencies is shown in figure 9. The peak in the plot of tangent loss $v s$. temperature is attributed to relaxation of dipoles (and ions) near $T_{\mathrm{g}}$, which shifts to higher temperature as the frequency is set at higher values (that is, from 0.12 up to $5.0 \mathrm{kHz}$ ). In $\mathrm{CdCl}_{2}$-doped PVA/PVAc-PVP blends, functional groups such as $\mathrm{OH}$ in $\mathrm{PVA} / \mathrm{PVAc}, \mathrm{C}=\mathrm{O}$ present in PVP and partially hydrolysed PVA (which are attached to the polymer backbone) are responsible for the occurrence of this peak [1]. Hence, this is said to be the $\beta$-relaxation. Here, one more possible relaxation is $\gamma$-relaxation which is caused by localized energy states formed by charge complexes created due to inter-/intra-molecular interactions between the molecules of PVA/PVAc and PVP with $\mathrm{CdCl}_{2}$. Formation of charge transfer complexes modifies the band structure of the PVA-PVP blend, on adding $\mathrm{CdCl}_{2}$ [55]. For $10.2 \mathrm{wt} \%$ of $\mathrm{CdCl}_{2}$ in the PVA/PVAc-PVP blend, the sample is amorphous in nature, but contains micro-globules of dopant encapsulated by polymer molecules [56]. In the amorphous region, polymer chains are flexible and mobile, and hence, the dipoles can orient themselves easily with the applied field at low frequency. Therefore, the $\tan \delta$ peak occurs at a temperature which is less than the value of $T_{\mathrm{g}}$ [57] for the sample with $10.2 \mathrm{wt} \% \mathrm{DL} \mathrm{CdCl}_{2}$ in the PVA/PVAc-PVP blend. 

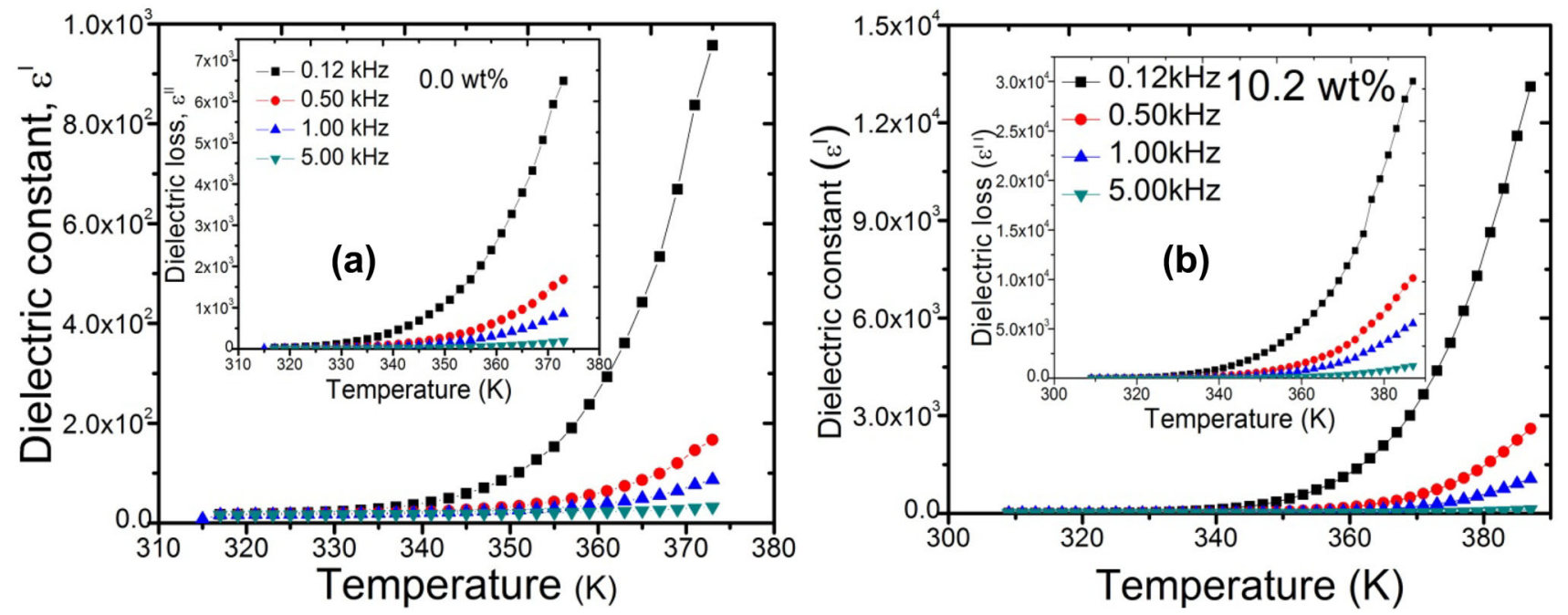

Figure 8. (a, b) Temperature dependence of dielectric constant $\left(\varepsilon^{\prime}\right)$ and dielectric loss $\left(\varepsilon^{\prime \prime}\right)$ (inset) at different frequencies: (a) for $0.0 \mathrm{wt} \%$ (un-doped PVA/PVAc-PVP blend film) and (b) for $10.2 \mathrm{wt} \% \mathrm{CdCl}_{2}$ in PVA/PVAc-PVP blend films.
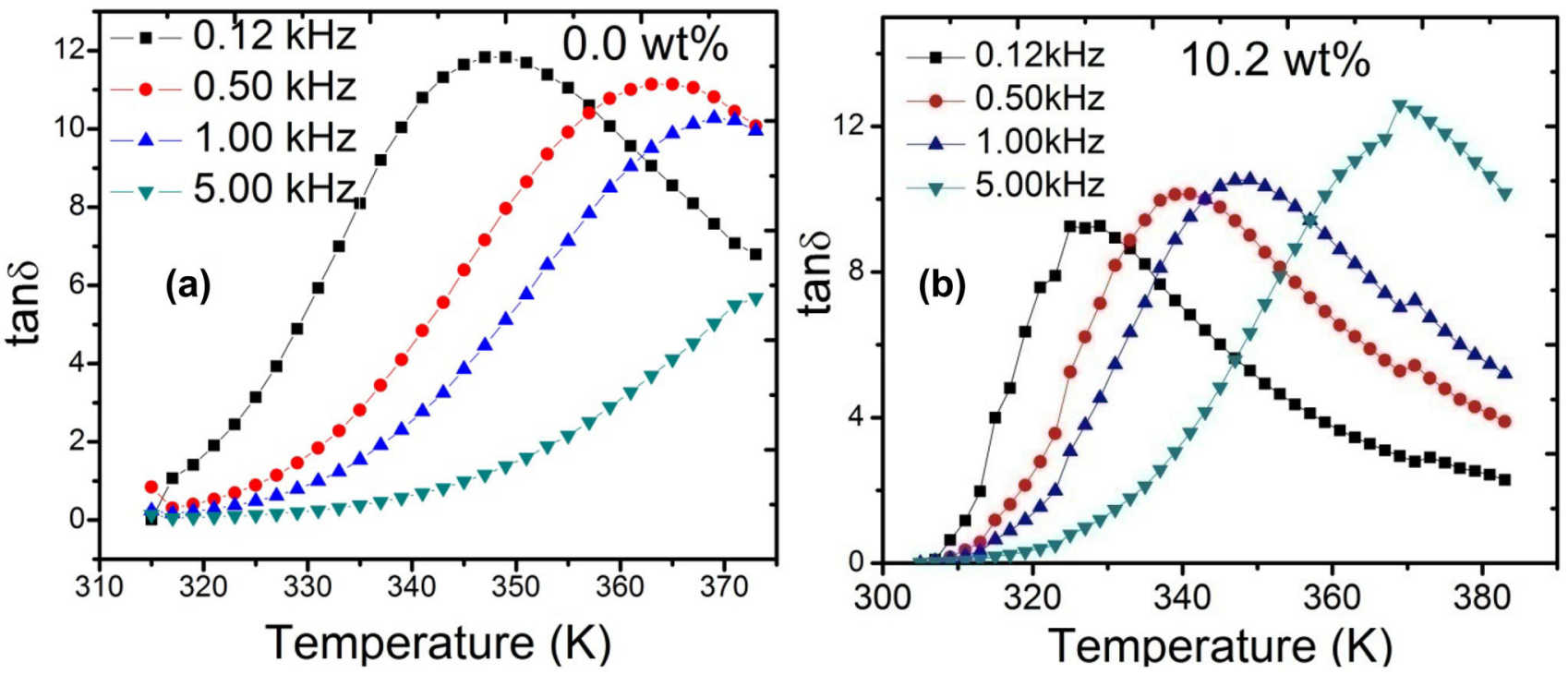

Figure 9. (a, b) Temperature-dependent tangent loss ( $\tan \delta$ ) at different frequencies: (a) for $0.0 \mathrm{wt} \%$ (un-doped) PVA/PVAc-PVP blend film, and (b) for film with $10.2 \mathrm{wt} \%$ of $\mathrm{CdCl}_{2}$ in the PVA/PVAc-PVP blend.

The position of the $\tan \delta$ peak decreases with an increase in frequency for the un-doped $(0.0 \mathrm{wt} \% \mathrm{DL})$ film, whereas it increases with frequency for the $10.2 \mathrm{wt} \% \mathrm{DL} \mathrm{CdCl}_{2}$-doped PVA/PVAc-PVP blend sample. This is because of the availability of more ions ( $\mathrm{Cd}$ and $\mathrm{Cl}$ ions) in the case of the doped sample, for accumulation at the electrolyte-electrode interface. The molecular packing is less in the $0.0 \mathrm{wt} \%$ sample when compared with the $10.2 \mathrm{wt} \%$ sample, because of crystalline regions comprising aggregated $\mathrm{Cd}$ microstructures in the doped film. Hence, for the $0.0 \mathrm{wt} \%$ (pure or un-doped) PVA/PVAc-PVP blend which is in an amorphous state, elastic restoring force binds the dipoles to their equilibrium positions. This is aided by the rotational frictional forces exerted by neighbouring dipoles. In the amorphous phase of the material, dipoles can orient themselves easily from one equilibrium state to another, which contributes to the absorption of energy over a wide range of frequency or temperature.

3.2d Electric modulus: The variation of the imaginary part and real part of electric modulus with temperature, at different frequencies, is shown in figure $10 \mathrm{a}-\mathrm{d}$. The intensity of electric modulus for the $10.2 \mathrm{wt} \% \mathrm{CdCl}_{2}$-doped PVA/PVAc-PVP blend film is double, when compared with the value for the un-doped (0.0 wt\% DL) PVA/PVAc-PVP blend film. This indicates that there is a contribution from dopant ions and grain boundaries present in the sample, for the conduction 

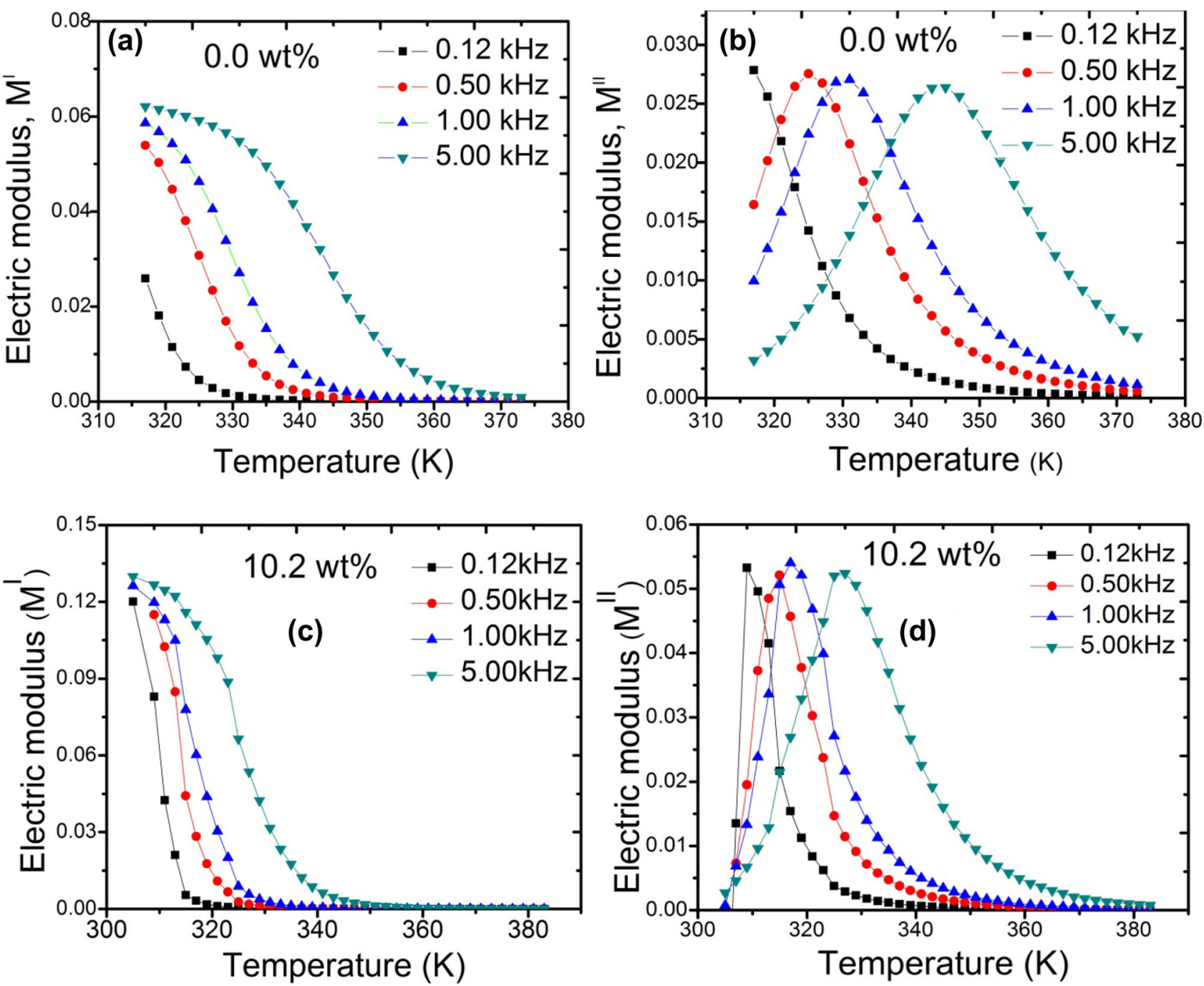

Figure 10. (a-d) Temperature dependence of (a and c) $M^{\prime}$ and (b and d) $M^{\prime \prime}$ at different frequencies, for un-doped and 10.2 wt $\%$ $\mathrm{CdCl}_{2}$-doped PVA/PVAc-PVP blend films.

process in the $10.2 \mathrm{wt} \% \mathrm{CdCl}_{2}$-doped PVA/PVAc-PVP blend film. From these plots, it is noted that the position of peak in the plot of $M^{\prime \prime} v s$. temperature shifts towards higher temperature, at larger frequencies. Due to self-grown micro-globules (grains), the $10.2 \mathrm{wt} \%$ sample is more crystalline when compared with the $0.0 \mathrm{wt} \%$ (pure) PVA/PVAc-PVP blend film [24]. Thus, because of the compact nature of polymer chains and ordered arrangement of $\mathrm{Cd}$ atoms, the shift in the position of $M^{\prime \prime}$ peak relative to an increase in temperature is smaller, when compared with that in the case of the un-doped (0.0 wt \%) PVA/PVAc-PVP blend sample.

3.2e Dopant concentration-dependent dielectric properties: The results of frequency- and temperature-dependent impedance spectroscopy for PVA/PVAc-PVP blend films, with $\mathrm{CdCl}_{2}$ DLs equal to 0.0 and $10.2 \mathrm{wt} \%$, have been discussed in the previous sections of this section.
Now, let us look at the dielectric behaviour of the PVA/ PVAc-PVP blend at different concentrations of $\mathrm{CdCl}_{2}$, at a fixed temperature equal to $299 \mathrm{~K}$. An interesting behaviour of the doped polymeric blend sample is observed on increasing the concentration of $\mathrm{CdCl}_{2}$ (in the PVA/PVAc-PVP blend film). The decrease in bulk conductivity $\left(\sigma_{\mathrm{b}}\right)$ (enhancement in bulk resistivity, $\rho_{\mathrm{b}}$; depending on the thickness of the sample, as can be inferred from equation (9)). This decrease in the value of bulk conductivity with an increase in dopant concentration is due to reduction in the concentration of available ions for conduction or transportation. This is due to interaction between the dopant $\left(\mathrm{CdCl}_{2}\right)$ and the polymer molecules (PVA/PVAc-PVP), there is a reduction of $\mathrm{Cd}^{2+}$ ions into $\mathrm{Cd}$ atoms; because of this, there are selfgrown nano-structures and micro-structures formed in the sample, followed by a percolation threshold at lower, moderate and higher dopant levels, respectively, of $\mathrm{CdCl}_{2}$ in the polymeric blend; this has been observed from DC electrical 

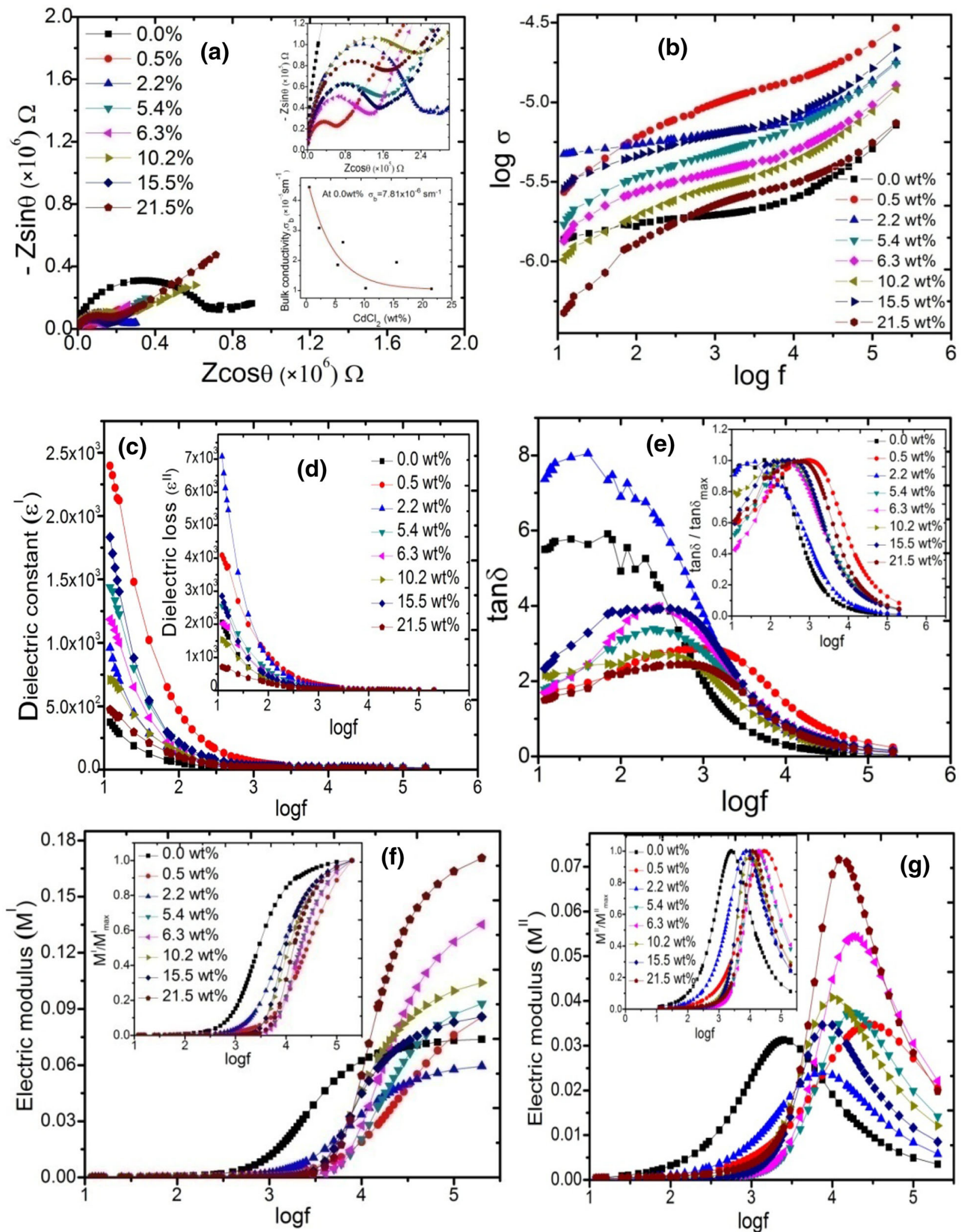

Figure 11. (a-g) Variation of dielectric parameters for films with different DLs of $\mathrm{CdCl}_{2}$ in the PVA/PVAc-PVP blend. (a) ColeCole plot, top inset shows a magnified portion, for low values of the real and imaginary axes of impedance; bottom inset shows variation of bulk conductivity. Frequency dependence of (b) $\log \sigma$, (c) dielectric constant, (d) $\tan \delta$, (e) $M^{\prime}$ and (g) $M^{\prime \prime}$ (insets in e, f and $\mathbf{g}$ show normalized graphs of respective values). 


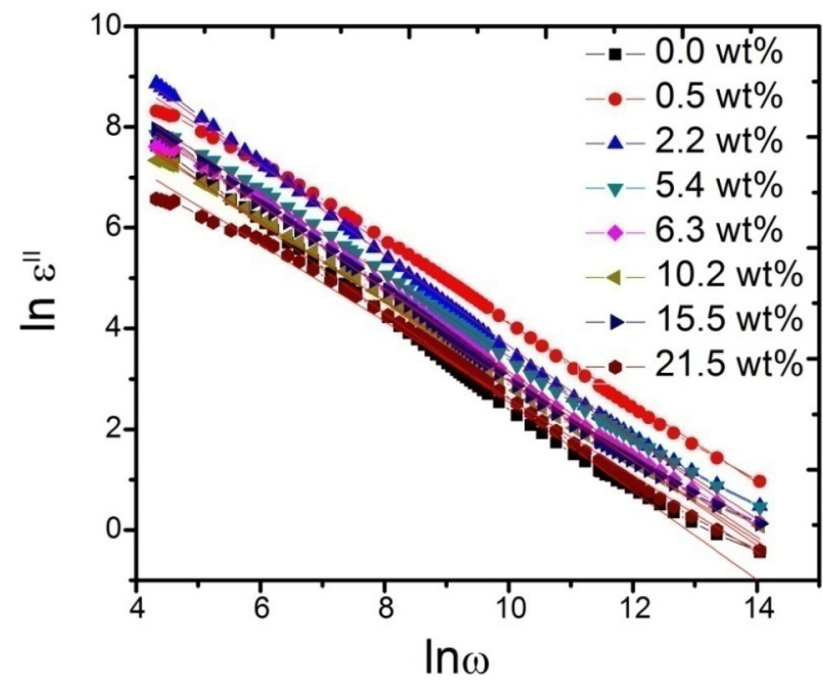

Figure 12. The plot of $\ln \varepsilon^{\prime \prime} v s$. $\ln \omega$, at different concentrations of $\mathrm{CdCl}_{2}$ in the PVA/PVAc-PVP blend.

measurements as well as dispersion parameters (from optical studies) [58,59]. In figure $11 \mathrm{~d}$, larger values of dielectric constant and dielectric loss are observed for 0.5 and $2.2 \mathrm{wt} \%$ samples; it is in these samples that $\mathrm{Cd}$ nano-spheres and $\mathrm{Cd}$ nano-rods are found; here, the polarization of $\mathrm{O}^{-}, \mathrm{H}^{+}$, $\mathrm{Cd}^{2+}$ and $\mathrm{Cl}^{-}$ions increase the interface area and so, there are more number of available charge carriers at low frequencies. As the concentration of $\mathrm{CdCl}_{2}$ in the PVA-PVP blend is increased from 5.4 up to $21.5 \mathrm{wt} \%$, there is a decrease in the values of $\varepsilon^{\prime}$ and $\varepsilon^{\prime \prime}$, which is due to decrease in the interface surface area, due to aggregation of nanoparticles. A similar effect has been observed in the case of PVA-ZnO nanocomposite [60]. Large value of $\tan \delta$ at lower frequencies is due to interfacial polarization, and the presence of a peak in the $\tan \delta$ spectra at all dopant levels of $\mathrm{CdCl}_{2}$ in the PVA/PVAc-PVP blend indicates that relaxing dipoles are present in all these samples. A larger shift in the $\tan \delta$ peak for the sample at DL equal to $0.5 \mathrm{wt} \%$ indicates that, in this sample, the dipoles have smaller relaxation time of orientation, and hence, they have accumulated at the electrolyte-electrode interface, leading to higher conductivity (see figure 11b). As $\mathrm{CdCl}_{2}$ concentration is increased from 5.4 up to $21.5 \mathrm{wt} \%$ in the PVA/PVAc-PVP blend, available ions are fewer in number, and charge carriers have shorter relaxation time; due to this, the dipoles cannot orient themselves in the direction of the applied AC field, and hence, there is a reduction in AC conductivity. The plots of real and imaginary parts of electric modulus in figure $11 \mathrm{f}$ and $\mathrm{g}$ show an increase in the intensity of relaxation peaks, which indicates that, with an increase of $\mathrm{CdCl}_{2}$ content in the PVA/PVAc-PVP matrix, there is a reduction in accumulation of ions across the electrode-electrolyte interface. Hence, there is a reduction in the capacitive effect.

The peak in the $M^{\prime \prime}$ spectra which is observed in the higher frequency region evidences the conduction process through polymer segmental motion and ions' movement, through the
Table 4. Dependence of $s$ and barrier potential $\left(W_{\mathrm{h}}\right)$ on the absolute temperature $(T=299 \mathrm{~K})$, at different $\mathrm{DLs}$ of $\mathrm{CdCl}_{2}$ in the PVA/PVAc-PVP blend film.

\begin{tabular}{lcc}
\hline $\mathrm{DL}(\mathrm{wt} \%)$ & $s$ & $W_{\mathrm{h}}(\mathrm{eV})$ \\
\hline 0.0 & $0.094 \pm 0.004$ & 0.1706 \\
0.5 & $0.195 \pm 0.003$ & 0.1920 \\
2.2 & $0.088 \pm 0.003$ & 0.1700 \\
5.4 & $0.181 \pm 0.003$ & 0.1886 \\
6.3 & $0.155 \pm 0.003$ & 0.1830 \\
10.2 & $0.150 \pm 0.003$ & 0.1818 \\
15.5 & $0.142 \pm 0.003$ & 0.1802 \\
21.5 & $0.192 \pm 0.004$ & 0.1912 \\
\hline
\end{tabular}

localized sites of the polymer matrix. The value of $s$ is calculated from the slope of linear fit, from the plot $\ln \varepsilon^{\prime \prime} v s . \ln \omega$ (as shown in figure 12). This is according to equation (13), in the maximum frequency range under study; the fitting (linear regression) is done in order to obtain the best fit parameter, between 0.9988 and 0.9993 . The calculated values of $s$ are listed in table 4 . These values show some fluctuations with a change in dopant concentration, but the range of $s$ values indicates that the electrical phenomenon obeys the CBH model. Barrier hopping energy $W_{\mathrm{h}}$ is also determined, and its value at different DLs is listed in table 4.

\section{Conclusions}

Frequency and temperature dependence study of dielectric parameters in un-doped and $\mathrm{CdCl}_{2}$-doped PVA/PVAc-PVP blend films reveals that, there is a significant change in these parameters due to the incorporation of $\mathrm{CdCl}_{2}$ in the PVA/PVAc-PVP blend. There is an increase in bulk conductivity of both $0.0 \mathrm{wt} \%$ (pure) and $10.2 \mathrm{wt} \% \mathrm{CdCl}_{2}$-doped PVA/PVAc-PVP blend films with increase in temperature. An increase in AC conductivity with temperature is due to increased segmental mobility and free volume in the PVA/PVAc-PVP polymeric blend. Larger number of ions can hop from one localized energy state to another through thermally activated processes, resulting in an increased AC conductivity. Since larger number of vibrational and rotational modes of motion is available, there is larger dielectric loss at higher temperatures. As the dipoles are unable to orient themselves with the applied field at higher frequency when compared with lower frequency, there is more dielectric loss at lower frequency. Ten times improvement in $\mathrm{AC}$ conductivity and smaller relaxation time is observed for the $10.2 \mathrm{wt} \% \mathrm{CdCl}_{2}$-doped PVA/PVAc-PVP blend film when compared with the $0.0 \mathrm{wt} \%$ (un-doped PVA/PVAc-PVP blend) film, which implies that, in addition to the side chain ions of the polymer molecules in the PVA/PVAc-PVP blend, there is a significant involvement of dopant ions $\left(\mathrm{Cd}^{2+}\right.$ and $\mathrm{Cl}^{-}$) in the process of $\mathrm{AC}$ conductivity in the $\mathrm{CdCl}_{2}-$ doped PVA/PVAc-PVP film. A decrease in AC electrical 
conductivity with an increase of $\mathrm{CdCl}_{2}$ concentration in the PVA/PVAc-PVP blend is due to reduction in the concentration of available ions for conduction or transportation, as these ions are involved in dopant-polymer interactions in the doped polymeric blend.

\section{References}

[1] Reddy C V S, Han X, Zhu Q Y, Mai L Q and Chen W 2006 Microelectron. Eng. 83281

[2] Nirmala Devi G, Chitra S, Selvasekarapandian S, Premalatha M, Monisha S and Saranya J 2017 Ionics 233377

[3] Vanitha D, Bahadur S A, Nallamuthu $\mathrm{N}$ and Athimoolam S 2018 Ionics 24139

[4] Sivadevi S, Selvasekarapandian S, Karthikeyan S, Sanjeeviraja C, Nithya H, Iwai Y et al 2015 Ionics 211017

[5] Vanitha D, Bahadur S A, Nallamuthu N and Manikandan A 2017 J. Inorg. Organomet. Polym. 27257

[6] Shahenoor Basha S K, Ranjit Kumar B, Veera Bhadra Reddy K and Rao M C 2017 Chem. Sci. Rev. Lett. 6832

[7] Premalatha M, Vijaya N, Selvasekarapandian S and Selvalakshmi S 2016 Ionics 221299

[8] Ramaswamy M, Malayandi T, Subramanium S, Srinivasalu J and Rangaswamy M 2017 Ionics 231771

[9] Khare P K and Jain S K 2000 Bull. Mater. Sci. 2317

[10] Polu A R and Kumar R 2011 Bull. Mater. Sci. 341063

[11] Aziz S B 2015 Bull. Mater. Sci. 381597

[12] Murugendrappa M V, Khasim S and Ambika Prasad M V N 2005 Bull. Mater. Sci. 28565

[13] Sarwar M I, Rafiq S, Yousaf S M and Ahmad Z 1998 Int. J. Polym. Mater. Polym. Biomater. 41185

[14] Link S and El-Sayed M A 1999 J. Phys. Chem. B. 1038410

[15] Nath N and Chilkoti A 2004 Anal. Chem. 765370

[16] Kulanthaisami S, Managalaraj D and Sa Narayandass K 1995 Eur. Polym. J. 31969

[17] Ahmed M A and Abo-Ellil M S 1998 J. Mater. Sci. Mater. Electron. 9391

[18] Rashmi, Narula G K and Pillai P K C 1987 J. Mater. Sci. 22 2006

[19] Sakthivel S, Chandar Shekar B, Mangalaraj D, Sa Narayadass K, Venkatachalam S and Prabhakaran P V 1997 Eur. Polym. J. 331747

[20] Bahri R and Singh H P 1979 Thin Solid Films 62291

[21] Ashcraft C R and Boyd R H 1976 J. Polym. Sci. Polym. Phys. B 142153

[22] Latha C and Venkatachalam K 2017 Polym. Bull. 743123

[23] Jeyabanu K, Siva V, Nallamuthu N, Selvanayagam S, Asath Bahadur S and Manikandan A 2018 J. Nanosci. Nanotechnol. 181103

[24] Baraker B M and Lobo B 2016 Indian J. Pure Appl. Phys. 54 634

[25] Hoffman J D, Williams G and Passaglia E 1966 J. Polym. Sci.: Polym. Symp. 14173

[26] Alberola N, Cavaille J Y and Perez J 1990 J. Polym. Sci. B: Polym. Phys. 28569

[27] Runt J P and Fitzgerald J J 1997 Dielectric spectroscopy of polymeric materials: fundamentals and applications (Washington (DC): American Chemical Society)
[28] Blochowicz T and Rössler E A 2004 Phys. Rev. Lett. 92225701

[29] Sundarakannan B, Kakimoto K and Ohsato H 2003 J. Appl. Phys. 945182

[30] Yadav V S, Sahu D K, Singh Y and Dhubkarya D C 2010 AIP Conf. Proc. 1285267

[31] Debye P 1929 (1st edn) Polar molecules (New York: Chemical Catalog Company)

[32] Cole K S and Cole R H 1941 J. Chem. Phys. 9341

[33] Qiao J, Fu J, Lin R, Ma J and Liu J 2010 Polymer 514850

[34] Malathi J, Kumaravadivel M, Brahmanandhan G M, Hema M, Baskaran R and Selvasekarapandian S 2010 J. Non-Cryst. Solids 3562277

[35] Ravi M, Pavani Y, Kumar K K, Bhavani S, Sharma A K and Narasimha Rao V V R 2011 Mater. Chem. Phys. 130442

[36] Raja V, Sharma A K and Narasimha Rao V V R 2004 Mater. Lett. 583242

[37] Hema M, Selvasekerapandian S, Sakunthala A, Arunkumar D and Nithya H 2008 Physica B $\mathbf{4 0 3} 2740$

[38] Rajeshwari N, Selvasekarapandian S, Prabhu M, Karthikeyan S and Sanjeeviraja C 2013 Bull. Mater. Sci. 36333

[39] Jonscher A K 1977 Nature 267673

[40] Funke K, Roling B and Lange M 1998 Solid State Ion. 105195

[41] Hirankumar G, Selvasekarapandian S, Bhuvaneswari M S, Baskaran R and Vijayakumar M 2006 J. Solid State Electrochem. 10193

[42] Hilker B, Fields K B, Stern A, Space B, Zhang X P and Harmon J P 2010 Polymer 514790

[43] Rao R V and Shridhar M H 2002 Mater. Lett. 5534

[44] Yang S, Benitez R, Fuentes A and Lozano K 2007 Compos. Sci. Technol. 671159

[45] Govindaraj G, Baskaran N, Shahi K and Monoravi P 1995 Solid State Ion. 7647

[46] Mohan V M, Qiu W, Shen J and Chen W 2010 J. Polym. Res. 17143

[47] Fan L, Dang Z, Wei G, Nan C W and Li M 2003 Mater. Sci. Eng., B 99340

[48] Roy A S, Gupta S, Sindhu S, Parveen A and Ramamurthy P C 2013 Composites B 47314

[49] Pradhan D K, Choudhary R N P and Samantaray B K 2009 Mater. Chem. Phys. 115557

[50] Pissis P and Kyritsis A 1997 Solid State Ion. 97105

[51] Pradhan D K, Choudhary R N P and Samantaray B K 2008 Express Polym. Lett. 2630

[52] Zhang S, Dou S, Colby R H and Runt J 2005 J. Non-Cryst. Solids 3512825

[53] Al-Hawarin J, Ayesh A S and Abdel-Rahem R A 2012 Chin. J. Polym. Sci. 30143

[54] Bhargav P B, Mohan V M, Sharma A K and Rao V V R N 2009 Curr. Appl. Phys. 9165

[55] Baraker B M, Hammannavar P B and Lobo B 2015 AIP Conf. Proc. 1665070037

[56] Baraker B M and Lobo B 2017 Can. J. Phys. 95738

[57] Marzantowicz M, Dygas J R, Krok F, Florjańczyk Z and Zygadło-Monikowska E 2007 J. Non-Cryst. Solids 353 4467

[58] Baraker B M and Lobo B 2017 Mapana: J. Sci. 1645

[59] Baraker B M and Lobo B 2017 J. Polym. Res. 2484

[60] Hemalatha K S, Sriprakash G, Ambika Prasad M V N, Damle R and Rukmani K 2015 J. Appl. Phys. 118154103 